\title{
3. DER PONTIFEX
}

\subsection{Clemens VI.: Biographischer Abriß}

Die Familie der Roger, der Clemens VI. entstammte, gehörte zur petite noblesse des Limousin und wurde zum ersten Mal im 12. Jahrhundert urkundlich erwähnt ${ }^{1}$. Stammsitz der Familie war Maumont, eine bescheidene Burg wenig außerhalb des Weilers Rosiers d'Egletons (Corrèze). Der Aufstieg der Familie von einem unbedeutenden Kleinadelsgeschlecht zu einem einflußreichen, wohlhabenden und ehrgeizigen Familienverband vollzog sich im 14. Jahrhundert ebenso rasch wie ephemer. Katalysator dieser Entwicklung war die Kirche und innerhalb dieser Pierre Roger, der 1342 den Thron Petri bestieg ${ }^{2}$. Nicht zuletzt dank seiner Patronage zählte die Familie im 14. Jahrhundert 24 Bischöfe und Erzbischöfe, 23 Kardinäle - mitgezählt werden die drei von Clemens VII. kreierten Purpurträger -, zwei Päpste und mit Hugues Roger, dem Bruder Clemens' VI., einen Kardinal, der das ihm angetragene Papstamt ablehnte ${ }^{3}$. Pierre Roger, geboren um 1290/12914 als Sohn des Guillaume Roger und der Guillemette de Mestre, hatte zwei Brüder und zwei Schwestern, Guillaume und Hugues, Bertrande und Almodie 5 . Almodie ehelichte Jacques de la Jugée, den Philipp VI. 1338 in den Adelsstand erhob ${ }^{6}$. Drei ihrer Söhne machten eine Karriere innerhalb der Kirche. Guillaume de la Jugée wurde von seinem Onkel in dessen erster Kreation 1342 zum Kardinaldiakon kreiert ${ }^{7}$, während sein Bruder Pierre mit kaum 20 Jahren Abt des

1 Baluze/Mollat, Vitae II, S. 335.

2 Einen biographischen Abriß liefern Mollat, Papes d'Avignon, S. 89-103; Guillemain, Cour pontificale, S. 137-140; Kurt A. Huber, Clemens VI. (Pierre Roger), in: Lebensbilder zur Geschichte der böhmischen Länder, Bd.3, hg.v. Ferdinand SEIBT, München, Wien 1978, S. 99-110. Die bisher einzige, wissenschaftlichen Ansprüchen genügende (politische) Biographie des Papstes stammt von WoOD, Clement VI; vgl. des weiteren FoURNIER, Pierre Roger; Paladilhe, Les papes d'Avignon, S.138-187; Art. Clemente VI (B. GullleMAIN), in: DBI 26 (1982), S. 215-222.

${ }^{3}$ Eine Aufstellung liefert Thrbault, Pope Gregory XI, Appendix A. Die Quarta Vita Clementis VI bemerkt: Hic ditavit omnes fratres suos, cujuscumque conditionis vel status essent, tam de beneficiis ecclesiasticis quam de thesauris et honoribus atque officiis et divitiis mundanis, BALUZE/MOLLAT, Vitae I, S. 294.

4 Vgl. Baluze/Mollat, Vitae I, S. 241; Vitae II, S.335, 341; vgl. auch WRIGLEY, Early life, S. 433. Clemens VI. äußerte sich selbst an einer Stelle seines Predigtcorpus zu seinem Alter. In einer Ansprache anläßlich der Kanonisierung des Heiligen Ivo am 19. Mai 1347 betonte er, daß er er selbst, derzeit (d.h. 1347) im 50. Lebensjahr stehend, an einem 19. Mai zum Papst erhoben worden sei und damit einiges mit dem Heiligen gemein habe, der, würde er noch unter den Lebenden weilen, zum Zeitpunkt seiner Kanonisation ebenfalls im 50. Lebensjahr stünde, vgl. Collatio Exulta et lauda habitatio Syon, MS 240, fol. 531r.

5 Baluze/Mollat, Vitae II, S. 336.

6 Ibid., S. 362.

7 Ibid., S. 365; EuBEL, I, S. 18. 
Klosters von Lagrasse (Diözese Carcassonne), mit 23 Jahren Erzbischof von Zaragossa und schließlich zwei Jahre später Erzbischof von Narbonne wurde $^{8}$. Der Dritte im Bunde, Hugues, wurde Ende 1349 Bischof von Béziers9. Die zweite Schwester, Bertrande, wurde die Gattin von Jacques de Besse. Der aus dieser Verbindung hervorgegangene Nicolas de Besse wurde von seinem Onkel 1344 zum Kardinaldiakon kreiert ${ }^{10}$. Der Bruder Clemens' VI., Hugues, verdankte seinen Aufstieg allein dem Papst. Als Benediktiner verbrachte er die ersten 40 Jahre seines Lebens in klösterlicher Stille, um danach im Fahrwasser seines Bruders einen glanzvollen Aufstieg zu vollziehen, der ihm neben einigen Abbatiaten sukzessive das Bistum Tulle und schließlich die Würde eines Kardinalpresbyters einbrachte ${ }^{11}$. Dem zweiten Bruder Clemens' VI., Guillaume, gelang der soziale Aufstieg ab 1333. Zu diesem Zeitpunkt - Pierre Roger amtierte als Erzbischof von Rouen - erwarb er das Lehen Rosiers vom Grafen von Ventadour. Während des Pontifikats seines Bruders wurde ihm von Jean, dem Thronerben Frankreichs, der Titel eines Vicomte de Beaufort verliehen ${ }^{12}$. Guillaume ging drei Ehen ein, aus denen insgesamt 13 Kinder hervorgingen, darunter auch Pierre Roger de Beaufort, der zukünftige Gregor XI., der von seinem Onkel Clemens VI. 1348 zum Kardinaldiakon kreiert wurde ${ }^{13}$. Clemens VI. beförderte also maßgeblich den Aufstieg seiner eigenen Familie und dies nicht erst als Papst, sondern bereits lange vorher.

1301 war er im Alter von erst 10 Jahren der Benediktinerabtei von La Chaise-Dieu in der Auvergne übergeben worden - das Schicksal des Zweitgeborenen ${ }^{14}$. Protegiert vom Abt und dem Bischof von Le Puy, wurde er 1307 als

8 Baluze/Mollat, Vitae IV, S. 61f., S.75f.; Eubel, I, S. 153.

9 Ibid., S. 137; BerLIERE, Suppliques de Clément VI, S. 212, n. 850.

10 Eubel, I, S. 18.

11 Baluze/Mollat, Vitae II, S. 354; Eubel, I, S. 18, 505.

12 Baluze/Mollat, Vitae IV, S.1. Zum weiteren Aufstieg dieses Familienzweigs vgl. THIBAULT, Gregory XI, S. 3-5.

13 Baluze/Mollat, Vitae I, S.269, 285; Eubel, I, S.18; vgl. die Genealogie der Familie Roger-Beaufort (cognatische Linie) bei Ludwig VoNEs, Urban V. (1362-1370). Kirchenreform zwischen Kardinalkollegium, Kurie und Klientel, Stuttgart 1998 (Päpste und Papsttum, 28), S. 544.

14 Vgl. zur Biographie bis zu Papstwahl Wrigley, Early life, S.433-473. Auch Jean de Cardaillac zeichnet den Lebensweg Clemens' VI. in seiner 1352 an der Kurie gehaltenen Traueransprache nach, vgl. Sermo Mortuus est David, BN ms. lat. 3294, fol. 206v-208v, hier fol.207r: [...] Nam a principio sue puerilis iuventutis Deum habuit in memoria, puer $X$ annorum religionem sancti Benedicti ingrediendo, et certe videmus, quod Deus ipsum non dedit oblivioni saltim in hoc mundo, quia in omni statu Ecclesie ipsum brevissimo tempore exaltavit in magisterio theologie, post ad gradum abbatie, tandem ad episcopalem et archiepiscopalem, post cardinalem, postremo papalem dignitatem ipsum promovendo. Igitur bene aparet, quod ipse non fuit oblitus Deum nec Deus ipsum [...]; vgl. zur bisher unedierten Predigt die Beschreibung der Handschrift in Catalogue général des Manuscrits latins, Bd. 5 (nn. 3278-3535), Paris 1966, S. 87-94, hier S.91; zur Person des Jean de Cardaillac vgl. EubeL, I, S. 82, 119, 121, 144, 427, 488; Guillaume MolLAT, Jean de Cardaillac, un prélat 
Student nach Paris geschickt und kam dort in einem Studienhaus des Ordens, wohl dem Collège de Narbonne, unter ${ }^{15}$. Pierre Roger widmete sich der Theologie, beschäftigte sich aber auch mit kanonischem Recht. Sein Auskommen fand er dank der Einkünfte aus den Prioraten von Saint-Pantaléon de Lapleau (1316), Savigny (1323) und Saint-Baudil (1324) ${ }^{16}$. Bereits zu dieser Zeit machte er durch profundes theologisches Wissen, erstaunliches Erinnerungsvermögen und rhetorische Fertigkeiten auf sich aufmerksam. In einem Brief des Kartäusers Heinrich von Kalkar, eines Schülers Buridans ${ }^{17}$, den er 1406 an seinen Mitbruder Johannes Dotz in Mainz richtete, finden einige Details Erwähnung, die den Studienaufenthalt Pierre Rogers in Paris näher beleuchten. Vielleicht aus einem Bedürfnis heraus, den allzusehr zur universitären Autorität erstarrten Buridan als Menschen mit Schwächen und Fehlern erscheinen zu lassen, überliefert Heinrich folgenden Bericht: Sowohl Buridan als auch Pierre Roger seien während ihrer Studienzeit in Liebe zum selben jungen Mädchen entbrannt, der Frau eines deutschen Schneiders. In einem Streit habe Buridan Pierre Roger so schwer am Kopf verletzt, daß diese Verletzung nicht nur eine große Narbe zur Folge gehabt habe, sondern auch als eigentlicher Grund für das erstaunliche Erinnerungsvermögen des späteren Papstes anzusehen sei ${ }^{18}$.

Die eigentlichen Studien schloß Pierre Roger mit dem Erwerb des Doktorgrades ab, der ihm auf Anweisung Papst Johannes' XXII. am 22. Juni 1323

réformateur du clergé au XIVe siècle, in: RHE 48 (1953) S.74-121; DERS., Jean de Cardaillac. Prélat, orateur et diplomate, in: HLF 40 (1974) S. 187-210.

15 Baluze/Mollat, Vitae I, S. 262, 274; Vitae II, S. 342; Thomas Sullivan, Benedictine monks at the University of Paris 1229-1500, Leiden, New York, Köln 1995, S. 296-299.

16 Über die Höhe eines Pfründeneinkommens in der ersten Hälfte des 14. Jahrhunderts gibt jetzt Auskunft William C. CourTENAY, Philosophy's reward: the ecclesiastical income of Jean Buridan, in: Recherches de théologie et philosophie médiévales 68 (2001) S. 163-170.

17 Léopold DelisLe, Un trait de la jeunesse de Buridan, in: Bulletin de la Société de l'Histoire de Paris et de l'Ile de France 2 (1875) S.101f., mit einem partiellen Abdruck des Briefes; vgl. auch Heinrich RÜTHING, Der Kartäuser Heinrich Egher von Kalkar (1328-1408), Göttingen 1967 (Veröffentlichungen des Max-Planck-Institutes für Geschichte, 18; Studien zur Germania Sacra, 8), S. 130; Die Korrespondenz und der Liber exhortacionis des Heinrich von Kalkar, hg.v. Arpád Peter Orban, Salzburg 1984 (Analecta Cartusiana, 111), S. 125.

18 DELISLE, Buridan, S. 102: [...] quem et vulneravit Buridanus graviter in capite ita quod fluxus sanguinis ipsius purgavit cerebrum suum et factus fuit ex tunc magnae memoriae in disputacionibus et sermonibus faciendis. Clemens' exzellentes Gedächntis war auch Gegenstand einiger Betrachtungen Petrarcas, vgl. Rerum memorandarum libri II, 14. Clemens VI. fungiert dort als Beispiel für die moderni; dazu auch BALUZE/MolLaT, Vitae I, S. 262: [...] necnon memorie mirabilioris esse; ibid., S. 274: [...] necnon memorie mirabilioris esse. Anhand der Schädelnarben konnte im Jahr 1790 das Grab Clemens' VI. in der Klosterkirche von La Chaise-Dieu identifiziert werden, vgl. Klaus BERGDOLT, Arzt, Krankheit und Therapie bei Petrarca. Die Kritik an Medizin und Naturwissenschaft im italienischen Frühhumanismus, Weinheim 1992, S.254, n. 24. 
vom Kanzler der Universität verliehen wurde ${ }^{19}$. In der Folge unterrichtete er wohl kanonisches Recht - nicht Theologie - und erwarb sich das Ansehen eines ausgewiesenen Spezialisten ${ }^{20}$. Dennoch beteiligte er sich an den theologischen Debatten seiner Zeit an prominenter Stelle. 1320/1321 maß er sich als Anhänger der Lehren des Thomas von Aquin ${ }^{21}$ in akademischen Disputationen mit den Franziskanern Pierre Auriol und François de Meyronnes ${ }^{22}$. In der Kontroverse um den Defensor pacis des Marsilius von Padua bezog er von Anfang an Stellung ${ }^{23}$. 1325 verfaßte er einen Johannes XXII. gewidmeten $\mathrm{Li}$ bellus, in dem er die vom Papst in dessen Dekretale Quia quorumdam mentes vorgenommene Verurteilung des Werks billigte und mit weiteren Argumenten stützte ${ }^{24}$. In Avignon nahm man seine dezidierte Parteinahme mit Wohlwollen zur Kenntnis. Am 23. Juni 1326 wurde er Abt von Fécamp und stand damit an der Spitze eines der drei wichtigsten Klöster Frankreichs ${ }^{25}$. Er war

19 Lettres communes Jean XXII, n. 17738; vgl. auch Charles V. LANGLoIs, Thomas de Baillie, chancelier de Paris, in: HLF 35 (1921) S. 303. Zu diesem Zeitpunkt hatte Pierre bereits 16 Jahre lang in Paris studiert. In dieser Zeit entstand auch ein Liber de paupertate Christi, zu dem der Bibliothekskatalog in Avignon vermerkt: compilatus per dominum Clementem papam VI dum erat magister Parisius, vgl. dazu Franz EHRLE, Historia bibliothecae Romanorum Pontificum tum Bonifatianae tum Avenionensis, Rom 1890, S. 288, n. 47; als Korrektiv zu Ehrle ist unverzichtbar Auguste Pelzer, Addenda et emendanda ad Francisci Ehrle Historiae Bibliothecae Romanorum pontificum, Vatikan 1947.

20 Giovanni Gaufredi, einer seiner Schüler, bezeichnete ihn später in seinem kanonistischen Traktat, dem Collectarium, als lucerna iuris.

21 Marie-H. Laurent, Pierre Roger et Saint Thomas d'Aquin, in: Revue Thomiste 36 (1931) S. 157-173.

22 Chris SCHABEl, Theology at Paris (1316-1345). Peter Auriol and the problem of divine foreknowledge and future contingents, Aldershot 2000, S. 149-155; Charles-Victor LANGLoIs, François de Meyronnes, frère mineur, in: HLF 36/1 (1924) S. 305-342; François de Meyronne, Pierre Roger, Disputatio (1320-1321), hg.v. Jeanne BARBET, Paris 1961; Francis Ruello, La notion thomiste de "ratio in divinis« dans la Disputatio de François de Meyronnes et de Pierre Roger (1320-1321), in: Recherches de théologie ancienne et médiévale 32 (1965) S. 54-75; zur weiteren Sekundärliteratur vgl. Olga WEJERS, Le travail intellectuel à la faculté des arts de Paris, Bd.2, Turnhout 1996, S. 94-98. Die den Sentenzen des Petrus Lombardus entnommenen Quaestionen und deren Bearbeitung durch Pierre Roger sind teilweise erhalten, vgl. Anneliese MAIER, Der literarische NachlaB des Petrus Rogerii (Clemens VI.) in der Borghesiana, in: Recherches de théologie ancienne et médievale 15/16 (1948/1949), I, S.332-356; II, S. 72-98. Die weiteren philosophisch-theologischen Kommentare des Pierre Roger sind aufgelistet in Peter ScHulthess, Ruedi IмBACH, Die Philosophie im lateinischen Mittelalter. Ein Handbuch mit einem bio-bibliographischen Repertorium, Zürich, Düsseldorf 1996, S.553f.

23 Marsilius von Padua, Defensor pacis, hg. und übersetzt von Horst Kusch, Werner Kunzmann, Berlin 1958; Jürgen MiethKe, Marsilius von Padua, die politische Philosophie eines lateinischen Aristotelikers, in: Lebenslehren und Weltentwürfe im Übergang vom Mittelalter zur Neuzeit, hg.v. Hartmut BoockManN, Göttingen 1989, S.52-76.

24 Die päpstliche Bibliothek in Avignon besaB eine Lectura domini Petri Rogeri super decretali Quorundam mentes, vgl. EHRLE, Historia, S.360, n. 958.

25 Lettres communes Jean XXII, n. 25735. Die beiden anderen Klöster waren Cluny und Saint-Germain-des-Prés. 
damit gleichzeitig drei Herren verpflichtet: dem Papst, dem französischen König Charles IV. und dem englischen König Edward III. Letzterer besaß die Normandie als Lehen der Krone Frankreichs: der Abt von Fécamp war somit sein Vassal. Lebensmittelpunkt blieb jedoch Paris, wo er als Berater des Königs wirkte, Aufgaben in der Chambre des Enquêtes wahrnahm und Renommee als hervorragender Prediger erwarb. Sein Aufstieg innerhalb der kirchlichen Hierarchie vollzog sich mit atemberaubender Geschwindigkeit. Am 3. Dezember 1328 erfolgte die Ernennung zum Bischof von Arras ${ }^{26}$, die Konsekration wurde am 12. März 1329 vorgenommen ${ }^{27}$. In seinem Bistum war Pierre Roger nur sporadisch anwesend. Die Administration erfolgte durch Bevollmächtigte ${ }^{28}$. Bereits Ende 1329 wurde er zum Erzbischof von Sens erhoben ${ }^{29}$, um nach nur einem Jahr Ende 1330 mit der Translation auf die bischöfliche cathedra von Rouen den vorläufigen Höhepunkt seiner Karriere zu erreichen ${ }^{30}$. Pierre Roger stand nun einem der reichsten Bistümer der Christenheit vor ${ }^{31}$. Der rasche Aufstieg auf der Karriereleiter war nicht nur auf die Protektion durch den französischen König bzw. die für ihn günstige Mortalität innerhalb des (nord)französischen Episkopats zurückzuführen, sondern hing mit der Rolle zusammen, die er 1329 auf der Versammlung von Vincennes gespielt hatte ${ }^{32}$. In eindrücklicher Rede hatte er dort die jurisdiktionelle Sonderstellung der Kirche gegen alle Übergriffe weltlicher Mächte verteidigt. Im September 1333 war er Mitglied einer aus bedeutenden Theologen zusammengesetzten Kommission, die sich in Avignon mit der von Johannes XXII. vertretenen Auffassung von der visio beatifica und der in diesem Zusammenhang vorgenommenen Verhaftung des Dominikaners Thomas Waleys beschäftigte ${ }^{33}$.

${ }^{26}$ Ibid., nn. 43418, 43496.

27 Baluze/Mollat, Vitae II, S. $342 f$.

28 Lettres communes Jean XXII, nn. 46170, 46171f.

29 Ibid., nn. 47435, 47817, 48278f.

30 IBID., nn. 51979, 51982, 52863, 52870f., 52880, 52883, 54111, 54586.

31 Salimbene von Parma hatte bereits 1250 die ökonomische Potenz des Bistums unterstrichen und in Hinblick auf den damaligen amtierenden Erzbischof Regaldus betont: Sed frater Regaldus hoc non est passus, quia dixit quod de medietate reddituum suorum poterat splendide vivere et decenter cum tota familia sua, et aliam medietatem habebat superfluam, vgl. Cronica, hg. v. G. SCALIA, Tumhoult 1999, S. 655, Z. 18-20.

32 Olivier Martin, L'assemblée de Vincennes de 1329 et ses conséquences, Paris 1909; Guillaume H. M. Posthumus Meyjes, Jean Gerson et l'assemblée de Vincennes (1329). Ses conceptions de la juridiction temporelle de l'Église, Leiden 1978; Jürgen MIETHKE, De potestate pape. Die päpstliche Amtskompetenz im Widerstreit der politischen Theorie von Thomas von Aquin bis Wilhelm von Ockham, Tübingen 2000, S. 184-204.

33 Vgl. Christian TrottmanN, La vision béatifique des disputes scolastiques à sa définition par Benoît XII, Rom 1995; dazu Kent EMERY, A forced march towards beatitude. Christian Trottmann's Histoire of the Beatific Vision, in: Vivarium 37 (1999) S. 258-281. Bereits zwei Jahre zuvor war er vom Papst dazu aufgefordert worden, dem französischen Königspaar die Verhaftung des Dominikaners zu erläutern - eine Aufforderung, der er nicht nachkam, vgl. Thomas KÄPPELI, Le procès contre Thomas Waleys O.P., Rom 1936. Auch in Avignon war er der einzige, der einer Verurteilung nicht zustimmte. 
Seit 1328 wurde Pierre Roger in die Auseinandersetzung zwischen Philipp VI. und Edward III. über das für die Guyenne zu leistende homagium einbezogen. Noch als Abt von Fécamp war er vom französischen König als Nuntius an den englischen Königshof entsandt worden ${ }^{34}$. Nicht zuletzt seinen Bemühungen war es zu verdanken, daß Edward III. am 6. Juni 1329 in der Kathedrale von Amiens Philipp VI. den Lehnseid leistete. An guten Beziehungen zu England war ihm auch als Erzbischof von Rouen gelegen, stand er doch in einem Lehnsverhältnis zu Edward III. Rouen entbehrte der Präsenz des Erzbischofs, der seinen Geschäften im Auftrag des Königs zumeist in Paris nachging, ab 1332 jedoch verstärkt in Avignon selbst von sich reden machte. Als Leiter einer Gesandtschaft, die Philipp VI. im Frühjahr 1332 an die Kurie entsandt hatte, oblagen ihm die Verhandlungen über einen neuen Kreuzzug ${ }^{35}$. In diesem Zusammenhang stellte er seine Fähigkeiten auch als Prediger unter Beweis: Vor Papst und Kardinälen hielt er eine Ansprache, nach der an der tatsächlichen Absicht des Königs, das Kreuz zu nehmen, keinerlei Zweifel mehr bestehen konnte ${ }^{36}$. Auch nach dem Verzicht des 1334 zum Papst gewählten Benedikt XII. auf den geplanten Kreuzzug war Pierre Roger weiterhin als Botschafter des Königs in Avignon tätig ${ }^{37}$. In Anerkennung seiner Verdienste um Königreich und Kirche wurde er in der einzigen von Benedikt XII. vorgenommenen Kreation 1338 zum Kardinal erhoben ${ }^{38}$. Dies bedeutete jedoch den Verzicht auf die umfangreichen Einkünfte, die er bisher aus dem Erzbistum Rouen bezogen hatte. Somit bestand die Notwendigkeit, sich um die Erweiterung des eigenen Benefizialbesitzes zu mühen, der fortan ein standesgemäßes Auskommen garantieren konnte ${ }^{39}$.

Als Kardinalpresbyter mit dem Titel SS. Nerei et Achillei ${ }^{40}$ galt Pierre Roger an der Kurie als Experte für englisch-französische Angelegenheiten.

34 Vgl. Eugène Déprez, Les préliminaires de la Guerre de Cent Ans. La Papauté, la France et l'Angleterre (1328-1342), Paris 1902, S.39-42; Marjorie ChIBNALl, Fécamp and England, in: L'Abbaye bénédictine de Fécamp, 3 Bde., Fécamp 1959-1961, hier Bd.1, S. $127-135$.

35 Kritisch dazu Franz J. Felten, Auseinandersetzungen um die Finanzierung eines Kreuzzuges im Pontifikat Johannes' XXII. (1316-1334), in: L'hostie et le denier. Les finances ecclésiastiques du haut Moyen Âge à l'époque moderne. Actes du colloque de la Commission internationale d'histoire ecclésiastique comparée (Genève, aout 1989), hg. v. Marcel Pacaut und Olivier Fatio, Genf 1991, S.79-99.

36 Collatio Faciem suam firmavit, MS 240, fol.290v-298v; Auszüge in BALUZE/MOLLAT, Vitae II, S.288f. Auch im folgenden Jahr war er in der selben Angelegenheit nochmals in Avignon präsent. Am 16. Juli 1333 hielt er die Ansprache Sanctissime pater et domine, in deren Folge Philipp VI. zum Generalkapitän des Kreuzzugs ernannt wurde, vgl. MS 240, fol. 298v-308v, fol. 495v-505v; DÉPREZ, Préliminaires, S. 105.

37 Vgl. Wrigley, Early life, S. 463f.

38 EuBEL, I, S. 17, n.3. Insgesamt wurden sieben Kardinäle neu ernannt.

39 Zum Benefizialbesitz vgl. WRIGLEY, Early life, S. 469f.

$40 \mathrm{Vgl}$. zu den beiden Heiligen IACOBUS DE VORAGINE, Legenda aurea, hg.v. Theodor GraEsSE, Breslau ${ }^{31890}$ (ND Osnabrück 1969), cap. 75, S. 338-340; ed. MAGGIONI, 
Die Sorge um diesen Konflikt sollte auch seine weitere Karriere bestimmen. Anfang Mai wurde er von den im Konklave versammelten Kardinälen zum Nachfolger des am 25. April verstorbenen Benedikt XII. gewählt. Die Wahl fiel damit auf eine Persönlichkeit, die sich in der königlichen Administration ausgezeichnet hatte, über vielfältige diplomatische Erfahrungen verfügte, als hervorragender Theologe und Kanonist galt und sich nicht zuletzt aufgrund rhetorischer Fähigkeiten hors du commun als würdiger Nachfolger empfahl. Seinen ihm nun obliegenden Pflichten eines obersten Hirten der Christenheit versuchte er nachzukommen, indem er ganz Europa mit einem dichten Netz von Nuntien und Legaten überzog, um aufflammenden Konflikten begegnen zu können ${ }^{41}$. Dabei schöpfte er vor allem aus dem personellen Reservoir des Kardinalskollegs. Kardinalizische Gesandtschaften gingen nach Aragon, wo die Invasion des Königreichs Mallorca durch den aragonesischen König verhindert werden sollte ${ }^{42}$. Ein weiterer Schwerpunkt päpstlicher Diplomatie lag in Italien ${ }^{43}$. Die Versuche zur Eindämmung der Macht Giovanni Viscontis blieben jedoch ergebnislos. 1352 war die Kurie sogar gezwungen, die Inbesitznahme Bolognas durch den Visconti im nachhinein zu legitimieren ${ }^{44}$. Die

S. 510-512; des weiteren LCI, Bd. 8, Sp. 34f. Eventuell erfolgte die Zuweisung der Titelkirche SS. Nerei et Achillei nicht zufällig. Bereits die von Jacobus de Voragine bemühte etymologische Herleitung des Namens Nereus legt einen Schwerpunkt auf die praedicatio und die conversatio. Pierre galt 1338 bereits als lucerna iuris und als magnus sermocinator. Was lag näher, als durch die Wahl der Titelkirche diesen Bezug sinnfällig vor Augen treten zu lassen? Noch weitere Elemente der Legende lassen sich mit der Lebenswirklichkeit des Kardinals und späteren Papstes in Verbindung bringen. Domitilla empfängt den Schleier aus den Händen des hl. Clemens. Dieser heilige Papst und Namensvorgänger markiert den Endpunkt einer außerordentlich erfolgreichen Konversionsgeschichte. Die Saat der von Nereus und Achilleus bewirkten praedicatio und conversatio geht in Domitilla auf, wird jedoch erst von Clemens durch den quasi-sakramentalen Akt der Einkleidung zur vollen Entfaltung gebracht. Domitillas Konversion ist ein Musterbeispiel für die Macht des Wortes, insbesondere der Predigt. Papst Clemens macht Domitillas Entscheidung zu einer rechtlich verbindlichen, markiert also zugleich oberste sakramentale und juridische Gewalt. Selbige Gewalt wird von den beiden Eunuchen kurz vor ihrem Martyrium verbal bemüht. Sie sterben nicht nur, weil sie Christen sind, sondern auch, weil sie die Taufe aus den Händen Petri, des Apostels und »ersten Papstes« empfangen haben. Welch schlagenderen Beweis für die spirituelle, auf das Wort gegründete Macht des Papstes kann es geben?

41 BALUze/Mollat, Vitae I, S.259: [...] valde fuit intentus ad procurandum statum pacificum et tranquillum suorum omnium subditorum [...]. Quod satis demonstravit in quasi assidua missione legatorum et nunciorum suorum, de qua supra sepe fecimus mentionem. Nec curavit se cum eis aut aliis in guerris involvere aut aliter dissensionibus intricare, nisi in quantum conservatio juris et honoris Ecclesie sibi commisse ipsum precise artarunt quandoque ad oppositum; et adhuc tunc per viam justitie processit, factum possetenus evitando.

42 Vgl. Ibid., S. 245, 264, $279 f$.

43 Jean de Cardaillac urteilt in seiner Totenpredigt auf Clemens VI. unrichtig: Ipse, inquam, manu fortis in potentia principatus contra ytalicos rebelles tempore suo mirabiliter triumphando, in: BN ms. lat. 3294, fol.207r.

44 Vgl. Giannina Biscaro, Le relazioni dei Visconti di Milano con la Chiesa. Giovanni e Luchino - Clemente VI, in: Archivio storico lombardo 54 (1927) S. 44-95, 201-236. 
vom römischen Volkstribunen Cola di Rienzo ausgehende Gefährdung schien man in Avignon lange zu unterschätzen. Erst Ende 1347 trug man mittels seines Kardinallegaten vor Ort zu seinem Sturz bei. Verwirrend war die Situation im Königreich Neapel, wo 1343 mit Johanna I. eine junge und unerfahrene Frau, Enkelin Roberts des Weisen, den Thron bestiegen hatte. Als oberster Lehnsherr nahm Clemens VI. für sich das Recht zu politischer Intervention in Anspruch, nicht um damit direkten Zugriff auf die Geschick des Königreiches zu erlangen, sondern der Unerfahrenheit und Verführbarkeit Johannas gegenzusteuern. Insbesondere nach der Ermordung ihres Gemahls Andreas von Ungarn am 18. September 1345 setzte der Papst alles daran, die territoriale Integrität Neapels gegen die Angriffe Ludwigs von Ungarn zu verteidigen. Dies gelang nur unvollkommen. Immerhin zeitigte die besondere Beziehung zwischen Papst und Königin ein für das Papsttum wichtiges Ergebnis: 1348 konnte Clemens VI. von Johanna I. die Stadt Avignon für 80000 Florin erwerben und damit Herr in seiner eigenen Residenzstadt werden.

Die in Hinblick auf den Konflikt zwischen England und Frankreich betriebene Friedenspolitik, deren einzige greifbare Ergebnisse die am 19. Januar 1343 und 28. September 1347 vermittelten Waffenstillstandsabkommen von Malestroit und Calais waren, wurde zumindest in der Anfangsphase von England als Parteinahme für Frankreich gewertet und von massiven Protesten gegen das päpstliche Provisionswesen begleitet. Tatsächlich gelang es dem Papst nicht immer, seine vorgebliche Unparteilichkeit aufrechtzuerhalten. Enorme Summen wurden von der Apostolischen Kammer an den französischen König zumeist als Kredit überwiesen ${ }^{45}$. Philipp VI. profitierte ebenso von den in Erwartung eines bevorstehenden Kreuzzuges konzedierten Zehntgeldern, die weil im Kampf gegen England dringender benötigt - zweckentfremdet wurden. Erfolgreicher agierte der Papst im Reich, wo er sich - der Linie seiner Vorgänger folgend - einer Verständigung mit Ludwig dem Bayern ${ }^{46}$ widersetzte und seinen eigenen Kandidaten durchsetzte: Karl von Luxemburg, der

45 Maurice FauCon, Prêts faits aux rois de France par Clément VI, Innocent VI et le comte de Beaufort (1345-1360), in: BEC 9 (1879) S. 570-578. Faucon liefert eine detaillierte Aufstellung der Summen, die von Clemens VI. und seinem Bruder Guillaume Roger dem französischen König zur Verfügung gestellt wurden. Die Zahlungen setzten am 26. November 1345 ein und endeten im Falle des Papstes am 17. Februar 1350. Rechnet man zu den gewährten Krediten die 2800000 Florin hinzu, die dem König als Vorauszahlung für den geplanten, jedoch niemals zustandegekommenen Kreuzzug zugeflossen waren, kommt man auf die enorme Summe von 3517000 Florin, die Philipp VI. zusätzlich zur Verfügung standen.

46 Hermann-Otto ScHwöbel, Der diplomatische Kampf zwischen Ludwig dem Bayern und der Römischen Kurie im Rahmen des kanonischen Absolutionsprozesses 1330-1346, Weimar 1968; Heinz ThомAs, Ludwig der Bayer (1282-1347). Kaiser und Ketzer, Regensburg 1993, S. 341-384; immer noch nützlich Karl RüMLER, Die Akten der Gesandtschaften Ludwigs des Bayern an Benedikt XII. und Klemens VI., in: Quellenstudien aus dem historischen Seminar der Universität Innsbruck 2 (1910) S. 111-155. 
am 11. Juli 1346 zum deutschen König gewählt wurde ${ }^{47}$. Als Karl IV. gelang es ihm, der bereits in jungen Jahren in Paris die Bekanntschaft des Pierre Roger gemacht hatte ${ }^{48}$, sehr schnell, das Verdikt des »Pfaffenkönigs« abzuschütteln und eine eigenständige, auf die Unabhängigkeit des Königtums von päpstlichen Wahlbestätigungen zielende Politik zu verfolgen ${ }^{49}$. Es gelang dem Papst nicht, die von seinem Vorgänger fallengelassenen Kreuzzugspläne wiederaufzunehmen. Allein eine von ihm vermittelte Liga, der Zypern, Venedig, die Hospitaliter und der Heilige Stuhl angehörten, vermochte es, militärische Erfolge zu erzielen. Im Kampf gegen die türkischen Emirate in Anatolien gelang im Oktober 1344 die Eroberung von Smyrna. Die daraufhin aufflammende Kreuzzugsbegeisterung der europäischen Mächte erlosch jedoch bald wieder ${ }^{50}$.

Das bereits von seinen Vorgängern ausgebaute Finanzsystem verfeinerte er dahingehend, daß systematisch alle Einkünfte aus Expektanzen und Provisio-

47 Die klare Parteinahme stieß zunächst auf Ablehnung bei Philipp VI. und führte zu verbalen Zusammenstößen zwischen Papst und König. Letzterer sah durch das päpstliche Vorgehen seinen Einfluß insbesondere in Flandern schwinden, vgl. hierzu MARTENS, La politique de Clément VI dans les principautés belges, S. 5-47; vgl. allgemein Peter MoRAw, Kaiser Karl IV. 1378-1978. Ertrag und Konsequenzen eines Gedenkjahres, in: Politik, Gesellschaft, Geschichtsschreibung. Gießener Festgabe für Frantisek Graus zum 65. Geburtstag, hg.v. Herbert LudaT und Rainer Christoph Schwinges, Köln, Wien 1982, S. 224-318; Heinz STOOB, Kaiser Karl IV. und seine Zeit, Graz 1990; Bernd-Ulrich HERGEMÓLler, Cogor adversum te. Drei Studien zum literarisch-theologischen Profil Karls IV. und seiner Kanzlei, Warendorf 1999.

48 In seiner Autobiographie beschreibt Karl IV., wie sehr er von einer Aschermittwochspredigt des Abtes von Fécamp, Pierre Roger, beeindruckt war: »Während ich ihm andächtig zuhörte und ihn betrachtete, gewann ich so tiefe religiöse Einsichten, daß ich mich fragen mußte: woran liegt es, daß von diesem Mann soviel Gnade auf mich überströmt? Endlich machte ich seine Bekanntschaft, und er förderte mich mit väterlicher Zuneigung und unterwies mich öfters in der Heiligen Schrift«, in: Vita Caroli Quarti. Die Autobiographie Karls IV. Einführung, Übersetzung und Kommentar von Eugen HillenBRAND, Stuttgart 1979, S. 87. Entgegen landläufiger Meinung war in Paris jedoch nicht Pierre Roger, sondern Pierre de Viviers der Erzieher Karls, vgl. Michel MARgue, Jean de Luxembourg et les rois de France, in: Un itinéraire européen. Jean l'Aveugle, comte de Luxembourg et roi de Bohême 1296-1346, hg.v. Michel Margue, Luxembourg 1996, S. 51-87. Die Predigt Clemens' VI. zur Approbation Karls IV. ist erhalten, vgl. Clemens VI. (Pierre Roger), Collatio facta per sanctissimum patrem ac dominum Clementem papam VI. in approbatione domini Karoli in Regem Romanorum, in: MGH. Constitutiones et acta publica imperatorum et regum, Bd.8, hg.v. Karl Zeumer, Richard SAlomon, Hannover 1910-1926, S. 143-163.

49 Vgl. Ludwig Schmugge, Kurie und Kirche in der Politik Karls IV., in: Kaiser Karl IV., Staatsmann und Mäzen, hg.v. Ferdinand SEIBT, München 1978, S.73-84; Gerhard SCHMIDT, Die Bistumspolitik Karls IV. bis zur Kaiserkrönung 1355, in: Karl IV. Politik und Ideologie im 14. Jahrhundert, hg.v. Evamaria ENGEL, Weimar 1978, S. 74-120; Roland PAUler, Die Auseinandersetzungen zwischen Kaiser Karl IV. und den Päpsten. Italien als Schachbrett der Diplomatie, Neuried 1996.

$50 \mathrm{Vgl}$. Norman Housley, The Avignon papacy and the crusades, 1305-1378, Oxford 1986, bes. S. 31-35. 
nen auf niedere Pfründen erfaßt wurden. Des weiteren sorgten ausgedehnte Ernennungs- und Kontrollvollmachten dafür, daß der Papst die Kontrolle über die kirchliche Hierarchie behaupten konnte. Als ein dem hierokratischen Denken eines Bonifaz VIII. verpflichteter Oberhirte verlieh der Papst seiner Stellung als vicarius Petri zusätzliche Bedeutung durch die Verwendung der Formeln vicarius Christi und vicarius Dei. Insbesondere mit letzterer Formel wurde der Anspruch auf ein unumschränktes Herrscheramt sinnfällig zum Ausdruck gebracht ${ }^{51}$, ein Amt, das sich über das gesamte Corpus Christi mysticum erstreckte und somit umfassender als die vom französischen König für sich reklamierte Gewalt über das Corpus reipublicae mysticum war $^{52}$. Der Machtanspruch des Papstes konkretisierte sich in seiner Vollgewalt, der plenitudo potestatis ${ }^{53}$, die sich über Geistliches und Weltliches erstreckte. Bereits von Gratian war der Bedeutungsgehalt dieses Terminus in enge Beziehung zur Stellung des Papstes als iudex ordinarius omnium gesetzt worden 54 . Angesprochen war also eine umfassende jurisdiktionelle Verfügungsgewalt, die als absolut, weil idealtypisch von niemandem außer dem Papst selbst beeinflußbar, gelten durfte. Bischöfe und Kardinäle hatten Anteil an dieser Vollgewalt, weil sie vom Papst in partem sollicitudinis berufen und damit dazu auserkoren waren, mit ihm zusammen die Last der Gesamtkirche

51 Vgl. Walter DüRIG, Der theologische Ausgangspunkt der mittelalterlichen liturgischen Auffassung vom Herrscher als vicarius Dei, in: Historisches Jahrbuch 77 (1958) S. 174-187. $52 \mathrm{Vgl}$. WoOD, Clement VI, S. 23; Ernst Kantorowicz, The King's Two Bodies, Princeton 1957, S. 232-249.

53 Die Entstehung und weitere Entwicklung des Begriffs in Abgrenzung zum Terminus pars sollicitudinis untersucht Robert BENSON, Plenitudo potestatis: evolution of a formula, in: Studia Gratiana 14 (1967) S. 196-217; vgl. des weiteren Gerhard B. LADNER, The concepts of "Ecclesia and »Christianitas « and their relation to the idea of papal »plenitudo potestatis « from Gregory VII to Boniface VIII, in: Sacerdozio e regno da Gregorio VII a Bonifacio VIII, Rom 1954, S. 49-77; Armin HoF, Plenitudo potestatis und imitatio imperii zur Zeit Innocenz' III., in: ZKG 66 (1954-1955) S. 39-71; Brian TIERNEY, Foundations of the conciliar theory. The contribution of the medieval canonists from Gratian to the Great Schism, Cambridge 1955, S. 141-149; John A. WATT, The theory of papal monarchy in the thirteenth century. The contribution of the canonists, New York 1965, S.75-105; DERS., The use of the term plenitudo potestatis by Hostiensis, in: Proceedings of the Second International Congress of Medieval Canon Law, hg.v. S. KutTNER, R. RYaN, Vatican 1965, S. 161-187; William David MCCREADY, Papal plenitudo potestatis and the source of temporal authority in late medieval papal hierocratic theory, in: Speculum 48 (1973) S. 654-674.

54 Vgl. WATT, Theory, S. 92-97; Jürgen MiETHKE, Geschichtsprozeß und zeitgenössisches Bewußtsein. Die Theorie des monarchischen Papats im hohen und späteren Mittelalter, in: HZ 226 (1978) S. 564-600; DERS., Der Weltanspruch des Papstes im späteren Mittelalter. Die politische Theorie der Traktate De Potestate Papae, in: Pipers Handbuch der politischen Ideen, Bd. 2 (1993), hg.v. Iring FETSCHER, S. 351-446; Klaus ScHATZ, Der päpstliche Primat. Seine Geschichte von den Ursprüngen bis zur Gegenwart, Würzburg 1990; Gilles LANGEVIN, Synthèse de la tradition doctrinale sur la primauté du successeur de Pierre durant le second millénaire, in: Il Primato del successore di Pietro. Atti del Simposio teologico (Roma, dicembre 1996), Città del Vaticano 1998, S.147-170. 
zu tragen ${ }^{55}$. Interessanterweise findet sich weder in der kurialen Korrespondenz noch in der Chronistik die Bezeichnung Pontifex maximus ${ }^{56}$.

An eine Rückkehr nach Rom dachte Clemens VI. ernsthaft zu keinem Zeitpunkt. Dabei konnte er sich freilich auf das kanonistisch abgesicherte Diktum Ubi papa, ibi Roma stützen, das die Präsenz des Papstes in Rom nicht zu einer Bedingung für die Ausübung seines Amtes machte ${ }^{57}$. Doch auch in Avignon wurde der Rombezug nicht vollständig aufgegeben, was nicht zuletzt die Patrozinien der Palastkapellen eindrucksvoll belegen. Die hervorgehobene Stellung der Ewigen Stadt war für den Papst unstrittig. In seiner Collatio anläßlich der Approbation Karls IV. bezog er sich auf die das römische Reich betreffenden translationes imperii, ohne dabei die Feststellung zu vergessen, das römische Reich dauere usque nunc. Vor diesem Hintergrund konnte er gar die Aussage wagen, das römische Imperium sei immer noch größer und mächtiger als alle anderen Gewalten ${ }^{58}$. Einer römischen Gesandtschaft, die 1343 Avignon erreichte, hatte er nur ausweichend auf deren Forderung geantwortet, die Kurie zurück nach Rom zu verlegen ${ }^{59}$. Frucht dieser diplomatischen Mission, an der auch Cola di Rienzo teilnahm, war die Gewährung eines Jubeljahres 1350 , was der Stadt immerhin einiges an ökonomischen Perspektiven eröffnete ${ }^{60}$. In Avignon selbst wurden sämtliche Entscheidungen selbstverständlich in curia romana getroffen ${ }^{61}$.

55 Jean Rivière, In partem sollicitudinis. Évolution d'une formule pontificale, in: Revue des sciences religieuses 5 (1925) S. 210-231. Mit Bernhard von Clairvaux hatte sich eine der Lieblingsautoritäten Clemens' VI. unmißverständlich zur Präzedenz des Papstes vor allen anderen Prälaten geäußert. In seiner Schrift De consideratione bemerkte er: Alii in partem sollicitudinis, tu in plenitudinem potestatis vocatus es, in: Sämtliche Werke, hg.v. Gerhard WINKLER, Bd. 2, Innsbruck 1992, S. 814, Z. 3f.

56 Vgl. Rudolf SchIEFFer, Der Papst als Pontifex maximus. Bemerkungen zur Geschichte eines päpstlichen Ehrentitels, in: ZRGK 57 (1971) S. 300-309, wo die These vertreten wird, daß die Geschichte des päpstlichen Ehrenprädikats erst um 1500 beginnt.

$57 \mathrm{Vgl}$. Konrad von Megenberg, Ökonomik, III.3, S. 404f.

58 Vgl. Collatio Salomon sedebit, in: MGH Constitutiones, Bd. 8, S. 150: [...] Et sicut dicitur Ezech. I, inter ista quatuor animalia facies aquile desuper erat, quia istud imperium Romanum maius et potentius ceteris fuit.

59 In Hinblick auf Rom ließ er keinen Zweifel an seiner Position, vgl. MS 240, fol. 148va: Roma est propria sedes summi pontificis et successoris Petri. Unde vocatur Romanus pontifex, Romanus episcopus. Sed arguitur contra, videtur, quod Roma non sit propria sedes papae. Probatur sic: sponsus universalis Ecclesie non habet propriam sedem, sed papa est sponsus universalis Ecclesie. Ergo non habet propriam sedem. Et sic secundum istum modum Roma non est sua propria sedes; dazu WooD, Clement VI, S. 74-96.

60 Heinrich SCHMIDINGER, Die Gesandten der Stadt Rom nach Avignon vom Jahre 1342/1343, in: Römische historische Mitteilungen 21 (1979) S. 15-33 (neu abgedruckt in Patriarch im Abendland. Beiträge zur Geschichte des Papsttums, Roms und Aquileias im Mittelalter. Ausgewählte Aufsätze von Heinrich Schmidinger. Festgabe zu seinem 70 . Geburtstag, Salzburg 1986, S. 169-189); Gabriel CoLOMBE, Nicolas Rienzi au palais des papes d'Avignon, in: Mémoires de l'Académie de Vaucluse 11 (1911) S.323-347; vgl. zur Romidee im Spätmittelalter Fedor SCHNEIDER, Rom und Romgedanke im Mittelalter, München 1925; Elisabeth KraACK, Rom oder Avignon? Die römische Frage unter den Päpsten 
Nur wenig Gutes hat die Forschung der letzten Jahrzehnte an der Person des Roger-Papstes gelassen. Immer wieder erwähnt wird sein Einsatz für die Juden Avignons und des Comtat Venaissin, die durch ihn vor den Verfolgungen und Pogromen in der Zeit der Pest 1348/1349 verschont blieben. Das Verhalten des Papstes hob sich in der Tat positiv von dem vieler anderer europäischer Herrscher $a^{6}{ }^{62}$, dennoch wird man neben Entrüstung über die gegen die Juden vorgebrachten Anschuldigungen auch politisch-ökonomisches Kalkül als Grund für den von ihm gewährten Schutz annehmen dürfen ${ }^{63}$. Energisch war sein Vorgehen gegen die Flagellanten, die - vom hohen Klerus zunächst

Clemens V. und Johann XXII., Marburg 1929; Johannes VINCKE, Zum Jubiläumsablaß des Jahres 1350, in: Römische Quartalschrift 49 (1954) S. 251-255; Eugenio DUPRE-THESEIDER, I Papi di Avignone e la questione romana, Florenz 1939; Percy Ernst SchramM, Kaiser, Rom und Renovatio, Darmstadt 1962; Otto KLUGE, Der Romgedanke von der Antike zur Renaissance, in: Das Gymnasium 52 (1941) S. 38-70; Max SEIDLMAYER, Rom und Romgedanke im Mittelalter, in: Saeculum 7 (1956) S.395-412; Heinrich SCHMIDINGER; Roma docta? Rom als geistiges Zentrum im Mittelalter. Antrittsvorlesung, gehalten am 15. Juni 1971 an der Universität Salzburg, Salzburg, München 1973; Raoul MANSELLI, I! papato avignonese e gli italiani del Trecento, in: Rapporti culturali ed economici fra Italia e Francia nei secoli dal XIV al XVI, Rom 1979, S.73-107; Josef BENZINGER, Invectiva in Romam. Romkritik im Mittelalter vom 9. bis zum 12.Jahrhundert, Lübeck, Hamburg 1968; John A. YUNCK, Economic conservatism, papal finance, and the medieval satires on Rome, in: Change in medieval society. Europe north of the Alpes, 1050-1500, hg.v. Sylvia L. ThRuPP, New York 1964, S. 72-85.

61 Vgl. Jean le Bel, Chronique, hg.v. Jean Viard, Eugène DéPrez, Paris 1904-05 (ND Genf 1977), c. 41, S.221. Dort wird betont, die Wahl Karls von Böhmen zum römischen König sei par la plus grande partie des esliseurs du roy d'Alemaigne, et par le consentement du pape Clement VI et par toute la court de Rome erfolgt.

62 Erinnert sei an Karl IV., der seinen servi camerae nur halbherzig zur Seite stand und die Auslöschung ganzer Judengemeinden billigend in Kauf nahm.

63 Vgl. allgemein zum Verhältnis der Avignon-Päpste zu den Juden Kenneth STow, The Avignonese Papacy or, after the Expulsions, in: From witness to witchcraft. Jews and judaism in medieval christian thought, hg. v. J. CoHEN, Wiesbaden 1996, S. 275-297, wo der päpstlichen Politik gegenüber den Juden eine wweltering inconsistency (S. 297) bescheinigt wird; des weiteren Léon BARDINET, Condition civile des juifs du Comtat Venaissin pendant le séjour des papes à Avignon (1309-1376), in: Revue Historique 12 (1880) S. 1-47; Ders., Les juifs du Comtat Venaissin au Moyen Âge: leur rôle économique et intellectuel, in: Revue Historique 14 (1880) S.29-35; Edward A. SYNAN, The popes and the jews in the Middle Ages, New York, London 1965; Joseph Shatzmiller, Les Juifs de Provence pendant la peste noire, in: Revue des Études juives 133 (1975) S. 457-480; William Chester JORDAN, The Jews and the transition to papal rule in the Comtat Venaissin, in: Michael 12 (1991) S. 213-232; speziell zum Umgang Clemens' VI. mit den Juden Diana WooD, Infidels and jews. Clement VI's attitude to persecution and toleration, in: Studies in Church History 21 (1984) S. 115-124; Dies., Clement VI, S.49-66; Solomon GraYZEL, The papal bull Sicut Iudeis, in: Essential papers on Judaism and Christianity in conflict. From late antiquity to the reformation, hg.v. John CoHEN, New York 1991, S. 231-260. Clemens VI. ist Schöpfer einer bis heute im Missale Romanum überlieferten Pestmesse, vgl. Jean VIARD, La messe pour la peste, in: BEC 61 (1900) S.334-338; Thilo EsSER, Pest, Heilsangst und Frömmigkeit. Studien zur religiösen Bewältigung der Pest am Ausgang des Mittelalters, Altenberge 1999, S. 60-118, 360-392. 
gebilligt - durch die Lande zogen und durch spektakuläre, 33\% Tage dauernde Manifestationen, darunter öffentliches Geißeln, versuchten, Gottes Zorn, der als ursächlich für den Ausbruch der Pest angesehen wurde, zu besänftigen ${ }^{64}$. Die Bewegung wurde durch die Bulle Inter sollicitudines vom 29. Oktober 1349 verboten ${ }^{65}$. Wie wichtig ihm das Vorgehen gegen tatsächlich deviante oder auch nur als solche empfundene Erscheinungen war und in welchen Formen sich dies manifestierte, zeigt sein Umgang mit dem franziskanischen Visionär Jean de Roquetaillade. Ihn hielt er zwar seit Oktober 1349 in Kerkerhaft und beschränkte so seine Kontakte zur Außenwelt, ermöglichte ihm jedoch die Weiterarbeit an seinen Schriften und stellte ihm die zu diesem Zweck nötige Literatur zur Verfügung ${ }^{66}$.

Seinen Gegnern lieferte Clemens VI. nicht wenige Angriffspunkte. Sein schrankenloser Nepotismus, durch den beispielsweise kaum 18jährige Neffen mit der Würde des Kardinalats bekleidet wurden, war ebenso sprichwörtlich wie die luxuriöse und ausgesprochen kostenintensive Ausgestaltung des Hoflebens ${ }^{67}$. Der ihm zugeschriebene Ausspruch »Unsere Vorgänger verstanden

64 Vgl. Catherine VINCENT, Discipline du corps et de l'esprit chez les Flagellants du Moyen Âge, in: Revue historique 615 (2000) S.593-614; Franz-Rainer ERKENS, Buße in Zeiten des Schwarzen Todes: Die Züge der Geissler, in: ZFH 26 (1999) S. 483-513; Stuart JENKs, Die Prophezeiung von Ps.-Hildegard von Bingen: Eine vernachlässigte Quelle über die Geißlerzüge von 1348/49, in: Mainfränkisches Jahrbuch für Geschichte und Kunst 100 (1977) S. 9-38; Étienne Delaruelle, Pourquoi n'y eut-il pas de flagellants en France en 1349?, in: DERS., La piété populaire au Moyen Âge, Turin 1975, S. 315-327; vgl. auch Paul FrederICQ, Deux sermons inédits de Jean de Fayt sur les Flagellants (5 octobre 1349) et sur le Grand Schisme d'Occident (1378), in: Bulletin de l'Académie royale de Belgique, classe des lettres, 1903, S.688-718.

65 Vgl. Froissart, Euvres, Bd. 5, S. 274-277.

66 Eine der wichtigen literarischen Ergebnisse aus der Zeit seiner Kerkerhaft war der $\mathrm{Li}$ ber de consideratione quintae essentiae, ein alchimistischer Traktat mit Ratschlägen zur Bekämpfung der Pest, vgl. hierzu Chiara CRISCIANI, Michela PereIRA, Black Death and golden remedies. Some remarks on alchemy and the plague, in: The Regulation of evil. Social and cultural attitudes to epidemics in the late Middle Ages, hg. v. Agostino Paravicini BAGLIANI, Francesco SANTI, Florenz 1998, S. 7-39, hier S. 13-22. Auch der Liber secretorum eventuum wurde im Gefängnis vollendet, vgl. Johannes de Rupescissa, Liber secretorum eventuum. Édition critique, traduction et introduction historique, hg.v. Robert LERNER und Christine MOREROD-FATTEBERT, Fribourg 1994; vgl. zur Vita des Franziskaners vor allem Bignami-Odier, Jean de Roquetaillade; Vones, Urban V., S. 45f.; Hannes MöHRING, Der Weltkaiser der Endzeit. Entstehung, Wandel und Wirkung einer tausendjährigen Weissagung, Stuttgart 2000, S. 279.

67 SCHÄFER, Ausgaben Klemens VI., S. 167-171, mit abwägendem Urteil auf S. 171: „Ein Hauptcharakterzug des Papstes ist seine außerordentliche Wohltätigkeit gegen Hilfsbedürftige und Arme [...]. Alles in allem betrachtet erscheint das Urteil eines modernen Historikers doch ungerecht, wenn er diesen Pontifikat so charakterisiert, als ob bloß zur Bestreitung der Kosten des Luxus und der Sinnenlust der päpstlichen Hofhaltung die Steuerschraube die Mittel habe liefern müssen $«$. Kritischer urteilt der Liber pontificalis, hg.v. Louis Duchesne, 2 Bde., Paris 1886/1892, hier Bd.1, S.491: Hic non modicum diminuit iura, iurisdictiones, libertates, thesaurum atque patrimonia beati Petri et Ecclesie Romane. Immerhin verdankt man dem Papst die Fertigstellung des unter Benedikt XII. begonne- 
es nicht, Papst zu sein« wird vor diesem Hintergrund verständlich ${ }^{68}$. Damit schien der Papst jedoch nicht allein seiner eigenen Meinung Ausdruck zu verleihen, sondern gleichzeitig die Unzufriedenheit weiter Kreise mit dem als zu streng und karg empfundenen Lebensstil seines direkten Vorgängers Benedikt XII. zu artikulieren. So enthalten beispielsweise die 1340 vollendeten Mélancolies des Jean Dupin in ihrem zweiten Teil eine Art Ständelehre, in deren Rahmen auch vom l'estat des Papes gehandelt wird ${ }^{69}$. In Hinblick auf Benedikt XII. zeichnet Dupin das Porträt eines Papstes, der sich menschenscheu hinter den dicken Mauern seines Palastes verbirgt und den Anforderungen seines Amtes in keinster Weise gerecht wird. Insbesondere wird der Verzicht auf eine prächtige Hofhaltung beklagt, die als Ausdruck der päpstlichen dignitas offenbar als unverzichtbar galt. Tatsächlich verringerte sich während des Pontifikats Clemens' VI. der Abstand zwischen Fest und Alltag ${ }^{70}$. Doch nicht nur in dieser Beziehung hob sich Clemens VI. von seinem Vorgänger $a b^{71}$. Auch die aus der Kongruenz zwischen Papstnamen und konkreter Tätigkeit resultierende Milde - clementia - war sprichwörtlich. Die Tertia vita Clementis $V I$. sieht in diesem Verhalten den Ausdruck einer Lebensmaxime, daß nämlich niemand die Kurie unzufrieden verlassen solle ${ }^{72}$. Die von Clemens VI.

nen Neubaus des Papstpalastes, vgl. KeRSCHER, Architektur als Repräsentation (mit umfassender Bibliographie); Fausto PIOLA CASElli, La costruzione del palazzo dei papi di Avignone (1316-1367), Milano 1981; Dominique Vingtain (Hg.), Monument de l'histoire. Construire, reconstruire le Palais des Papes, XIVe-XXe siècle, Avignon 2002; des weiteren Bernhard SCHIMMELPFENNIG, Die Organisation der päpstlichen Kapelle in Avignon, in: QFIAB 50 (1971) S. 80-111; DERS., Die Zeremonienbücher der römischen Kurie im Mittelalter, Tübingen 1973 (Bibliothek des Deutschen Historischen Instituts Rom, 40); Ders., Die Funktion des Papstpalastes und der kurialen Gesellschaft im päpstlichen Zeremoniell vor und während des Großen Schismas, in: Genèse et débuts du Grand Schisme d'Occident, Paris 1980, S. 317-328; DERS., Der Palast als Stadtersatz. Funktionelle und zeremonielle Bedeutung der Papstpaläste in Avignon und im Vatikan, in: Zeremoniell und Raum, hg.v. Werner PARAVICINI, Sigmaringen 1997, S. 239-256; René FAGE, Les gants et la croix reliquaire du pape Clément VI, in: Bulletin de la Société des Lettres, Sciences et Arts de la Corrèze 36 (1914) S. 115-120.

68 Baluze/Mollat, Vitae I, S. 298: Predecessores nostri nesciverunt esse papa; vgl. hierzu Mollat, Étude critique, S. 105-110.

69 Jean BATANY, Benoît XII et la construction du palais jugés par un moraliste contemporain, in: Avignon au Moyen Âge. Textes et documents, Avignon 1988, S. 67-73; vgl. auch Les Mélancolies de Jean Dupin, hg. v. Lauri Lindgren, Turku 1965.

70 Vgl. WeIss, Versorgung, S. 298.

71 Dieses »Anderssein « wurde jedoch insbesondere in der Forschung des 19. Jahrhunderts negativ bewertet, vgl. Johannes HALler, Das Papsttum von Avignon und das Reformprogramm des XV. Jahrhunderts, in: DERS., Papsttum und Kirchenreform. Vier Kapitel zur Geschichte des ausgehenden Mittelalters, Berlin 1903, S. 1-195, bes. S. 123.

72 Baluze/Mollat, Vitae I, S. 275: Nam recte, sicut scriptum est, lex clementie in lingua ipsius, que sibi tantum naturaliter inerat quod Cesarianum illud memorabile verbum coram semper habebat, quempiam non decere, videlicet de presentia principis non contentum abire; dazu Mollat, Étude critique, S.34-41; zur Wahl des Papstnamens Bernd-Ulrich Hergemöller, Die Geschichte der Papstnamen, Münster 1980, S. 130-132, wo der Name Clemens VI. als Bekenntnis zum Vorgängerpapst Clemens V. und dessen Politik gewertet 
insbesondere zu Beginn seines Pontifikats demonstrierte Milde in Benefizialangelegenheiten gab Anlaß zu wütenden Protesten ${ }^{73}$. Die päpstlichen Rechnungsbücher belegen eine außerordentliche Milde gegenüber Armen und Bedürftigen ${ }^{74}$. Das ihm insbesondere von Matteo Villani und Petrarca unterstellte ausschweifende Liebesleben muß jedoch ins Reich der Legende verwiesen werden ${ }^{75}$. Avignon wurde unter Clemens VI. zu einem der wichtigsten kulturellen Zentren Europas insbesondere in Hinblick auf den Austausch neuester künstlerischer Entwicklungen zwischen Nord und Süd ${ }^{76}$. Anstöße zu einer

wird: "Der Name ist demnach eindeutiges Zeichen seiner profranzösischen Haltung und seiner positiven Einstellung zum Verbleib der Päpste in der Grafschaft Venaissin«; vgl. auch Ulrich KRÄMER, Über Ursprung und Ursache des Papstnamens, in: Römische Quartalschrift 51 (1956) S. 148-188.

${ }^{73}$ Beispielhaft in dieser Beziehung ist ein Schreiben des Lütticher Klerus, in dem auf die Nachteile hingewiesen wird, die aus einer allzu großzügigen Reservationspraxis durch den Papst resultieren, vgl. SchOolmeEsters, Recueil, S.28-34. Die Konflikte zwischen denjenigen, die sich auf die von Clemens verfügten Generalreservationen beriefen und denjenigen, die aufgrund einer gratia specialis bereits im Besitz einer Pfründe waren, führten in einigen Bistümern zum Zusammenbruch einer geregelten Benefizialvergabe. Gleichwohl geißelte der Papst selbst die Pfründengier vieler Kleriker, vgl. Collatio Ecce rex tuus, in: MS 240, fol.102ra: Cum factus quis fuerit in quacumque ecclesia decanus, prepositus, archydiaconus aut aliquis hujusmodi non contentus, ymmo in una plures sibi quotquot valet conquirere honores satagit tam in una quam in pluribus quibus tamen omnibus, si locus advenerit libenter prefert unius episcopi dignitatem, sed nunquam satiabitur, sic factus episcopus archiepiscopus esse desiderat, quo adepto rursum nescio, quod alterius sompnians laboriosis itineribus et sumptuosis familiaritatibus Romanum statuit frequentare palatium, questuosas sibi quasdam exinde comparans amicitias et cum magistro suo Lucifero usque ad astra progreditur; vgl. als Gegenbeispiel Jean de Cardaillac, Sermo Mortuus est David, BN ms. lat. 3294, fol. 207r: Ipse David vultu desiderabilis, ipse enim, ut nostis, aspectu, convictu, affatu, clementia, liberalitate toti mundo desiderabilis et gratulabundus [...]; vgl. allgemein Guillaume Mollat, Les grâces expectatives sous le règne de Philippe VI de Valois, in: RHE 32 (1936) S. 303-312; Ders., Les grâces expectatives du XII ${ }^{e}$ au XIVe siècle, in: RHE 42 (1947) S. 81-102; Sabine WEISs, Päpstliche Expektanzen in Theorie und Praxis, in: Ecclesia peregrinans. Festschrift Josef Lenzenweger, Wien 1986, S. 143-152.

74 SCHÄFER, Ausgaben Klemens VI., S. 181. 17\% des Gesamthaushaltes wurden demnach jährlich für wohltätige Zwecke aufgewandt; vgl. auch Tertia Vita Clementis VI, in: BALUZE/ Mollat, Vitae I, S.287: Nam pro derelictis orphanis maritandis et pauperibus viduis sustentandis, necnon et indigentibus nobilibus adjuvandis, et oppressis debitorum oneribus relevandis, per mundissimas manus reverendi patris domini Guillelmi, tunc archiepiscopi, nunc tituli Sancte Marie in Transtiberim presbiteri cardinalis, quem de tenendo secreto sacramento pariter et mandato perstrinxit, ultra centum milia florenorum misericorditer erogavit. $75 \mathrm{Vgl}$. Guillaume MolLAT, Clément VI et la vicomtesse de Turenne, in: MEFR 73 (1961) S. 375-389; John E. Wrigley, A rehabilitation of Clement VI: Sine nomine 13 and the Kingdom of Naples, in: AHP 3 (1965) S. 127-138.

76 Verwiesen sei hier insbesondere auf den Stellenwert, der der Ars Nova in der päpstlichen Kapelle zugebilligt wurde und auf die Bedeutung der im päpstlichen Palast geförderten Malerei, als deren bekanntestes und zukunftsweisendstes Ergebnis wohl das ikonographische Programm der Chambre au Cerf angesehen werden muB; vgl. Étienne ANHEIM, Diffusion et usage de la musique polyphonique mesurée (ars nova) (France du midi, nord de l'Espagne et de l'Italie, 1340-1430), in: Cahiers de Fanjeaux 35 (2000) S. 287-323; John E. Wrigley, Pétrarque et l'appartement pontifical de Clément VI, in: Actes du Congrès 
Kalenderreform gingen vom Papst direkt aus ${ }^{77}$. Auch wenn sich Clemens VI. erfolgreich als Mäzen der Humanisten betätigte, wäre es dennoch verfehlt, in ihm selbst einen Vertreter des Frühhumanismus erblicken zu wollen. Seine literarische Hinterlassenschaft deutet vielmehr auf ein Festhalten an alten, überkommenen, scholastisch sanktionierten Denkstrukturen hin.

Seit langem gesundheitlich anfällig ${ }^{78}$, starb Clemens VI. am 6. Dezember 1352 in Avignon, wo auch die Trauerfeierlichkeiten stattfanden. Seine letzte Ruhestätte fand der Papst jedoch in dem von ihm bereits zu Lebzeiten mit immensem Kostenaufwand in Auftrag gegebenen Grabmal in der Abtei von La Chaise-Dieu ${ }^{79}$.

international Francesco Petrarca, Père des Renaissances, serviteur de l'Amour et de la Paix, Avignon 1974, S. 132-149; Ders., Petrarch's Sine nomine 10. The historical pseudonyms and art symbolism, in: Francis Petrarch, six centuries later. A symposium, hg.v. Aldo SCAGLIONE, Chapel Hill, Chicago 1975, S. 278-304; Christian MÉRINDOL, Clément VI, seigneur et pape, d'après le témoignage de l'emblématique et de la thématique. La Chambre du Cerf, l'Abbatiale de La Chaise-Dieu, in: Cahiers de Fanjeaux 28 (1993) S. 331-361; William O. DUBA, Moral edification, the search for truth, and the papal court. Pierre Roger (Clement VI) and the intellectual atmosphere of Avignon, in: La vie culturelle, intellectuelle et scientifique à la cour des papes d'Avignon, hg. v. Jacqueline Hamesse, Turnhout 2006, S. 303-319.

77 Eugène DEPrez, Une tentative de réforme du calendrier sous Clément VI. Jean de Murs et la Chronique de Jean de Venette, in: MEFR 19 (1899) S. 131-143; Christine GACKSCHEIDING, Johannes de Muris. Epistola super reformatione antiqui calendarii. Ein Beitrag zur Kalenderreform im 14. Jahrhundert, Hannover 1995 (MGH Studien und Texte, 11); Chris ScHABEL, John of Murs and Firmin of Beauval's letter and treatise on calendar reform for Clement VI, in: Cahiers de l'Institut du Moyen Âge Grec et Latin 66 (1996) S.187-215; Ders., Ad correctionem calendarii. The Background to Clement VI's initiative?, in: Cahiers de l'Institut du Moyen Âge Grec et Latin 68 (1998) S. 13-34.

78 Vgl. zur Gesundheit des Papstes Lettres Clément VI, nn.532, 965, 1671, 1672, 3004, 3771, 4143; Lettres Clément VI autres que la France, nn. 2565, 2573; BALUZE/Mollat, Vitae I, S.303: [...] percussus apostemate in dorso [...] ipsius apostema erumpens et cor ejus submergens, subito exspiravit; BALUZE/MOLLAT, Vitae II, S. 423; Eugène DEPREZ, Les funérailles de Clément VI et d'Innocent VI d'après les comptes de la cour pontificale, in: MEFR 20 (1900) S. 235-250; Henri WAQUET, Note sur les médecins de Clément VI, in: MEFR 32 (1912) S. 45-48; GuILLEMAIN, Cour pontificale, S. 376-382; vgl. Jean de Cardaillac, Sermo Mortuus est David, BN ms. lat. 3294, fol.207r: Huic Dominus tantam gratiam condonavit, ut in senectute bono, antequam ad laborem et dolorem decrepitus pertingeret, ad celi curiam vocaretur.

${ }^{79}$ Das Grabmal - von den Hugenotten 1562 zu großen Teilen zerstört - umfaßte ein plastisches, aus 44 Figuren bestehendes Dekor, das zumeist nahe Verwandte abbildete und somit noch im Tod von der großen Verbundenheit des Papstes mit seinen nepotes kündete, vgl. SCHÄFER, Ausgaben Klemens VI., S. 451f.; Maurice FAuCON, Le tombeau du pape Clément VI dans l'église de la Chaise-Dieu, in: Bulletin de la Société des Lettres, Sciences et Arts de la Corrèze, 1885, S.117-133; Ernst STEINMANN, Die Zerstörung der Grabdenkmäler der Päpste in Avignon, in: Monatshefte für Kunstwissenschaft 11 (1918) S.1-27; Ernest VINCENT, Tombeaux des papes limousins d'Avignon, in: Bulletin de la Société archéologique et historique du Limousin 86 (1956) S. 287-296; André FAYARD, Le tombeau de Clément VI à La Chaise-Dieu, in: Almanach de Brioude et de son arrondissement 42 (1962) S. 39-82; Viva G. WETTERLÖF, Les ymagiers à la cour des papes d'Avignon et à la cour des rois de France 1327-1365, Lund 1975, S. 206-222; Frédérique-Anne CostaNTINI, 


\subsection{Clemens VI. als maximus sermocinator verbi Dei}

Clemens VI. galt als größter Rhetor seiner Zeit und hatte bereits vor seiner Wahl zum Papst durch spektakuläre Ansprachen auf sich aufmerksam gemacht ${ }^{80}$. Die von seiner Umwelt als exzeptionell begriffenen oratorischen Fähigkeiten ebneten ihm den Weg nicht nur in das innere Beratergremium des französischen Königs ${ }^{81}$, sondern förderten auch seinen raschen Aufstieg innerhalb der kirchlichen Hierarchie. Als facundia eloquentissimus ${ }^{82}$, als vir maxime scientie et excellentis eloquentie ${ }^{83}$ wurde er zum Musterbeispiel eines

L'abbatiale Saint-Robert de La Chaise-Dieu: un chantier de la papauté d'Avignon (1344-1352), Paris 2003.

Das Trauergefolge, das die sterblichen Überreste des Papstes in die Auvergne begleitete, umfaßte allein fünf Kardinalnepoten (Hugues Roger, Guillaume de la Jugée, Nicolas de Besse, Pierre Roger de Beaufort, Guillaume d'Aigrefeuille). Die täglichen Predigten während dieser Zeit hielt Pierre Thomas. Im Verbund mit der Heiligen Jungfrau soll Clemens VI. bereits ein kleines Wunder gewirkt haben, indem er dem heiseren Prediger wieder seine Stimme verliehen und ihn zur Abfassung der schönsten, von ihm bisher gehaltenen Predigt veranlaßt haben soll, vgl. The life of Saint Peter Thomas by Philipp de Mézières, hg.v. J. SMET, Rom 1954, S. 62f.: Ipso autem coram Deo sic clarescente, sic regente in curia, Dominus Papa Clemens debitum universae carnis solvit, et debitis exequiis solemniter completis, funus eius in quodam monasterio Casa Dei vocato portatum fuit, et ab Avinione usque ad praedictum locum fecerunt duodecim dietas. Ipse autem Frater Petrus ab omni parentela papae et collegio electus fuit ad praedicandum in itinere, et fecit duodecim sermones in itinere, quolibet die unum, mirabiles sed et ultra quam mirabiles. Beata ergo Virgo Maria, quae tantum sublimaverat devotum sum Fratrem Petrum, iterum voluit ipsum honorare. Nam funere papae existente in ecclesia Beatae Mariae de Pugio, Frater Petrus ascendit cathedram ut praedicaret more solito, et propter labores itineris et praedicationes praecedentes invenit se ita raucum quod loqui minime poterat nec audiri. Ipse / autem scandalum non posse praedicandi timens incurrere, vertit se ad imaginem beatae Mariae, orationem suam devote fundens. Qua finita, Virgine adiuvante, et populo audiente incepit alta voce thema suum, et praedicavit taliter et ita clare sicut alios sermones unquam fecerat. Quam gratiam a beata Virgine sibi factam ipse Frater Petrus, sicut mihi dixit, ipsi beatae Mariae et meritis beatae memoriae Papae Clementis attribuit.

80 SCHNEYER, Repertorium der lateinischen Sermones des Mittelalters, Bd. 4, S. 757-769; MOLLAT, L'œuvre oratoire; SCHMITZ, Sermons; WoOD, Sermon literature; LÜTZELSCHWAB, Non solum assumuntur. Allein der Artikel von Diana Wood behandelt in groben Umrissen die Rezeption des Predigtwerks in späteren Jahrhunderten. Das verdienstvolle Werk Schneyers soll vervollständigt und auf die Zeit des Spätmittelaitters ausgedehnt werden, vgl. Ludwig HödL, J. B. Schneyer, Repertorium der lateinischen Sermones des Spätmittelalters, in: Scriptorium 53 (1999) S. 145-159; Kap. 3.2.

81 Philipp VI. soll den Plänen Johannes' XXII., Pierre Roger zum Kardinal zu erheben, energisch entgegengetreten sein, quia nullam habebat amaritudinem conversatio ejus, sed letitiam et gaudium, vgl. BALUZE/MOLLAT, Vitae I, S. 263, 274.

82 Vgl. die Aussagen des Jean de Cardaillac in seiner Traueransprache auf Clemens VI: [...] et ita aparet, quod nulli parcit, quia nec Christo pepercit, aparet etiam de isto nostro David, domino Clemente, qui fuit in scientia maximus, facundia eloquentissimus, sapientia astutissimus, toti mundo conversationis dulcedine acceptissimus ac divitiis potentissimus [...], in: Sermo Mortuus est David, fol. 208r.

83 Heinrich von Diessenhofen, Historia ecclesiastica sive chronicon, in: Fontes rerum Germanicarum, hg. v. Friedrich BöHMER, Bd. 4, S. 16-126, hier S. 86. 
wirkmächtigen Predigers ${ }^{84}$. Eine ihm gewidmete und Philippe de Vitry zugeschriebene Motette bezeichnet ihn gar als »Pauke der Predigt«, dessen Worte allen Gram aus den Herzen vertreibe und dem Ohr gleich einem Instrument schmeichle ${ }^{85}$. Von seinem Ansehen auf diesem Gebiet zeugen mehr als hundert, über ganz Europa verstreute Handschriften, in denen einzelne oder mehrere seiner Predigten überliefert sind ${ }^{86}$. Bereits die päpstliche Bibliothek in Avignon verfügte über eine stattliche Anzahl von Handschriften, die Predigten des Papstes enthielten ${ }^{87}$. Eine besondere Stellung nimmt dabei die heu-

84 Als weitere Belege aus der zeitgenössischen Chronistik sind anzuführen: Die Weltchronik des Mönchs Albert, hg. v. Rolf SPRANDEL, München 1994 (MGH SS n.s., 17), S. 105-111, hier S.111: Hic nichil intemptatum reliquit, in factis suis omnibus et vita, plusquam debuit, secularis existens, scientie tamen ornatus et ultra, quam credi posset, eloquentissimus; Les Grandes Chroniques de France, hg.v. Jean Viard, Bd.9, S. 224: Ycestui pape Climent fu homme de grant lecture et docteur en theologie, et sus touz autres en son temps, il ot grace de preschier et de bien et graceusement parler; Guillaume de Nangis, Chronique latine, hg. v. Hercule GÉRAud, Paris 1843, Bd.2, S. 105: Hoc eodem anno rex misit in Angliam ad regem nuntios, scilicet magistrum Petrum Rogerii abbatem Fiscampnensem, doctorem in theologia, virum summae memoriae et ultra modum communem hominum eloquentem, cum pluribus aliis; Aymeric de Peyrac, zit. in Mollat, Euvre oratoire, S. 239f.: maximum sermocinatorem verbi Dei; auch in drei der sechs Vitae Clementis VI finden sich entsprechende Hinweise, vgl. Prima Vita, ed. Baluze/Mollat, Vitae I, S. 259f.: sermones et collationes excellentissime etiam sepe faciendo; in quibus etsi retroactis temporibus forte quandoque habuerit sibi pares excedentes tamen raro, prout talium tenor adhuc penes plures permanens indicat manifeste; Tertia Vita, ibid., S.288: eloquentie flos; Quarta Vita, ibid., S. 289: Hic fuit vir magne divinitatis scientie atque fons sermocinorum; Vita Caroli quarti, hg. v. Johann Fr. BöHMER, in: Fontes rerum Germanicarum, Stuttgart 1843, Bd.1, S.235: Fuitque unus inter consiliarios suos, vir prudentissimus, Petrus abbas Fiscaniensis nacione Lemovicensis, homo facundus et litteratus, omnique morum honestate circumseptus, qui in die cinerum anno primo regni Philippi missam celebrans sic industriose predicavit, quod ab omnibus fuit commendatus. Placuit autem michi predicti abbatis facundia seu eloquencia in eodem sermone, ut tantam contemplacionem haberem in devocione ipsum audiens et intuens, quod intra me cepi cogitare dicens: Quid est quod tanta gracia michi infunditur ex homine isto?; Historiae Romanae Fragmenta, hg. v. Ludovico A. MURATORI, in: Antiquitates Italicae medii Aevi, Bd.3, Mailand 1740, S. 344: gratissimus fuit sermocinator. Quum cathedram concionaturus aut disputaturus ascendebat, tota Parisiorum civitas, ut eum audiret, accurebat. Proh quam eleganter sermocinabatur!; Thomas Walsingham, Chronica Monasterii S. Albani (Historia Anglicana), hg.v. Henry Thomas RILEY, Bd.1, S.254: Eodem anno [1342], Clemens Sextus, quondam Rothomagensis Archiepiscopus, successit Benedicto Duodecimo. Iste Clemens vir insignis litteraturae fuit, sed prodigalitatis profusissimae; vgl. auch BALUZE/MOLLAT, Vitae II, S. 422f.

$85 \mathrm{Vgl}$. Mildred Jane JoHnson, The motets of the Codex Ivrea, PhD Indiana University, 2 Bde., 1955, hier Bd.2, S. 172, Takte 107-113; vgl. Ernest H. SANDERS, Art. Philippe de Vitry, in: The New Grove 20 (1980) S.22-28.

86 Schneyer verzeichnete bereits 101 Predigtincipits, die von Diana Wood nochmals um 20 Incipits ergänzt wurden, vgl. WOOD, Sermon literature, S.164; dazu auch Kathrin WALSH, Klemens VI. und Stift Stams. Predigttätigkeit in Avignon und Frühhumanismus in Tirol am Beispiel von MS 234 der Universitätsbibliothek Innsbruck, in: Studien und Mitteilungen zur Geschichte des Benediktinerordens und seiner Zweige 92 (1981) S. 205-219.

87 Vgl. EhrLE, Historia, S. 333, n. 589 (sermones domini Clementis); S. 415, n. 1783 (sermones domini Clementis); S. 428, n. 1996 (magnus liber sermonum domini Clementis pape VI, 
te unter der Signatur MS 240 in der Bibliothèque Sainte-Geneviève zu Paris aufbewahrte Handschrift ein, die einen Großteil seines Predigtwerks überliefert $^{88}$. Bereits Friedrich Bock sah in ihr eine Art »Hauptcodex«, vom Papst selbst in Auftrag gegeben, versäumte es jedoch, Gründe für diese Behauptung anzuführen $^{89}$. Tatsächlich scheint Clemens VI. das Manuskript selbst in Auftrag gegeben zu haben. Die päpstlichen Rechnungsbücher verzeichnen zwei auf die Jahre 1346 und 1352 datierte Zahlungen an Schreiber, die damit beschäftigt waren, bis zu 46 Pergamentbögen mit den Predigten Clemens' VI. zu füllen ${ }^{90}$. Allein die Anzahl der kopierten Sermones läßt eine Identifizierung der beschriebenen Pergamentbögen mit dem Codex der Bibliothèque SainteGeneviève keinesfalls abwegig erscheinen ${ }^{91}$. Die Predigten Clemens' VI. wurden bis weit ins 15. Jahrhundert hinein geschätzt und galten als Muster, derer man sich für die Ausarbeitung eigener Predigten bediente. Die moderne Historiographie erkennt zwar die oratorische Begabung des Papstes an, unterscheidet jedoch in den meisten Fällen akribisch zwischen Inhalt und Form der Predigten ${ }^{92}$. Während die Form gepriesen wird, finden sich in Hinblick auf den Inhalt nur wenige uneingeschränkt positive Stimmen ${ }^{93}$. Selbst wenn man das Gebiet der historischen Wissenschaft verläßt und den Blick auf die Romanproduktion der letzten Jahrzehnte lenkt, fällt auf, daß Vertreter des Genre »Historischer Roman« die rhetorischen Fertigkeiten Clemens' VI. in ihre Romanstruktur integrieren, sich also ein letzter Rest dieses bereits die Zeitgenossen faszinierenden Phänomens in die Gegenwart hinübergerettet hat ${ }^{94}$. In

copertus corio rubeo); vgl. auch S. 213 , n. 4; S.218, n. 24; S. 474, n.280, S. 524, n. 1145, S. 556, n. 1603; vgl. allgemein Daniel WiLliman, Bibliothèques ecclésiastiques au temps de la papauté d'Avignon, Bd. 1, Paris 1980.

$88 \mathrm{Vgl}$. Charles KoHLER, Catalogue des manuscrits de la Bibliothèque Sainte-Geneviève, Bd.1, Paris 1893, S.146.

89 Friedrich Bock, Reichsidee und Nationalstaaten, München 1943, S. 503.

90 EHRLE, Historia, S. 163-165: Pro quodam volumine de sermonibus domini nostri pape in quo sunt XXXVII sexterni, tam pro pergamenis, LXXXII flor., V sol., VI den. [9. Juni 1346]; Item sunt scripte tam collationes quam sermones de novo facte per dominum nostrum papam post alios magnos sermones qui sunt in uno magno volumine III librorum; in quibus quidem collationibus seu sermonibus de novo factis sunt $X$ sexterni [9. November 1352]; dazu auch Mollat, Euvre oratoire, S. 262; zur Datierung der Handschrift vgl. Kap. 9.1.1. 91 Der Aufbewahrungsort des Manuskripts bis ins 17. Jahrhundert ist unbekannt, vgl. KOHLER, Catalogue, S.146.

92 Vernichtend urteilt Böhmer, in: Regesta imperii, S.504, n. 8a: »Künstlich, aber ungenießbar! «

93 Vgl. Lenzenweger, Acta pataviensia austriaca, I, S.175; Mollat, Papes d'Avignon, S. 90; Mollat, Euvre oratoire, S. 261, 274.

$94 \mathrm{Vgl}$. hier beispielsweise der Abschnitt in dem ansonsten farblosen Machwerk von Marianne CalmanN, Die Schöne von Avignon, München 2001 (Original London 1999), S. 356: „Klemens war ein gelehrter Mann, dessen Worte weit über den Horizont der meisten seiner Zuhörer hinausgingen. Aber er hatte eine Methode gefunden, auch die Ungebildetsten in seinen Bann zu ziehen: er spielte mit Worten. Manchmal versuchte er es mit einem Schwall von Wörtern, die alle den gleichen Anfangsbuchstaben hatten, manchmal wählte er ein Wort mit mehreren Bedeutungen und stellte verschiedene Gedanken einander 
seiner Formgestaltung zeigte sich Clemens VI. sehr stark einer Schule verhaftet, die mit der Ausbildung einer genuin scholastischen Predigtstruktur stilbildend gewirkt hatte. Insbesondere in Paris, wo Pierre Roger über Jahrzehnte zunächst als Student, dann als Lehrer tätig war, wurde diese Form gepflegt.

In einem idealtypisch konstruierten Sermo, von unzähligen Predigtlehren zur Nachahmung empfohlen, wurde ein der Bibel entnommenes Zitat, das als Thema diente, über ein Prothema, anschließend die Divisio, Distinctio und Dilatatio entfaltet ${ }^{95}$. Das Thema mußte kurz und prägnant sein und in direktem Zusammenhang mit den folgenden Abhandlungen stehen. Über die mit der Auswahl des Themas verbundenen Schwierigkeiten informiert Clemens VI. in seiner Collatio Super montem excelsum, wo er unterstreicht, daß jeder Konsistorialansprache ein individuelles, ad personam zugeschnittenes Element eigne, das bereits im Thema zum Ausdruck kommen müsse ${ }^{96}$. Die in einer Ansprache zu ehrenden Personen, zumeist Kardinäle, sind mithin nicht Empfänger einer Allerweltspredigt, sondern profitieren von den auf sie persönlich ausgerichteten Predigtinhalten.

Die Aufgaben des sich idealiter anschließenden Prothema waren vielgestalt ${ }^{97}$. Prothemen enthielten des öfteren eine Anrufung Gottes um Hilfe im Predigtamt. Damit verbunden waren Reflexionen theoretischer Natur über Aufgaben und Ziele von Predigt im allgemeinen ${ }^{98}$. Clemens VI. verzichtete in seinen Konsistorialansprachen auf ein Prothema. Dies geschah zum einen vor

gegenüber - so als betrachtete man die geschliffenen Facetten eines Diamantrings von allen Seiten. Seine Worte waren das Werkzeug, mit dem er die verschlossenen, manchmal halsstarrigen Hirne für seine Gedanken öffnete, und er gab sich mit jeder Predigt unendlich viel Mühe!«; vgl. des weiteren den ohne größere literarische Ambitionen verfaßten Roman von Claude Mossé, Le château des Papes, II: Les bâtisseurs, Paris 2000, in dem Clemens VI. eine zentrale Rolle spielt. Die Aussage »Comme dans le premier volume de cette série, personnages réels ou imaginaires se croisent et s'entrecroisent. Rien n'est faux, tout n'est pas vrai « gilt dabei auch für die beiden weiteren, Avignon behandelnden Romane des Autors, darunter Clément V, Paris 1998 und Le château des Papes, I: Les intrigants, Paris 2000.

95 Vgl. zur Geschichte der Predigt Dorothea Roth, Die mittelalterliche Predigttheorie und das Manuale Curatorum des Johann Ulrich Surgant, Basel, Stuttgart 1956 (Basler Beiträge zur Geschichtswissenschaft, 58); Johann-Baptist SCHNEYER, Geschichte der katholischen Predigt, Freiburg i. Br. 1969, bes. S.154-171; LONGĖRE, La prédication médiévale; vgl. auch den innovativen Ansatz von Michael MENZEL, Predigt und Geschichte. Historische Exempel in der geistlichen Rhetorik des Mittelalters, Köln, Weimar, Wien 1998; Jacqueline HAMESSE (Hg.), Medieval Sermons and Society. Cloister, City, University, Kalamazoo 1998; KIENZLE, Sermon, S. 737-742.

96 Vgl. Kap. 4.7.

97 Johann-Baptist SCHNEYER, Die Unterweisung der Gemeinde über die Predigt bei scholastischen Predigern. Eine Homiletik aus scholastischen Prothemen, München, Paderborn, Wien 1968; Thomas-Marie Charland, Artes praedicandi. Contribution à l'histoire de la rhétorique au Moyen Âge, Paris, Ottawa 1936, S.127f.; KIENZLE, Sermon, S.397, 737f.

98 Für Schneyer stellen die Prothemen »eine der wichtigsten, vielleicht sogar die wichtigste Quelle für die scholastische Predigttheorie dar", sind sie für ihn doch \#Ausdruck der Selbstbesinnung der Prediger auf ihre Aufgaben«, vgl. SCHNEYER, Unterweisung, S. 8, 12. 
dem Hintergrund der sozialen Zusammensetzung seiner Zuhörerschaft, die allgemein gehaltene Aussagen über die Bedeutung des Predigtamts obsolet werden ließ, zum anderen aufgrund der Tatsache, daß eine mit der Einführung eines Prothemas verfolgte Form von allectio ebenso unnötig schien. Als Papst war Clemens VI. nicht gezwungen, seine Zuhörerschaft für das Kommende zu begeistern.

Die Divisio ordnete den Hauptteil der Predigt. Eingeleitet wurde dieses Herzstück jeder Predigt durch eine Erläuterung der Einzelteile, aus denen das bereits vorgestellte Thema bestand und um deren synthetische Darstellung jeder Prediger bemüht sein sollte. Die zentralen Inhalte innerhalb der Divisio konnten mittels eines argumentativen oder narrativen Stils vermittelt werden. Clemens VI. bevorzugte einen eher argumentativen Stil und erwies sich damit als Vertreter der gebildeten, scholastisch geprägten Universitäts- und Klerikerpredigt. Die Methodenvielfalt bei der Unterteilung und Ausbreitung des Themas innerhalb der Divisio war erstaunlich, doch blieb im Falle Clemens' VI. ein Punkt bestimmend: die Bevorzugung der Dreizahl. In drei, höchstens vier Punkten, sollte der Inhalt des Themas erschöpfend behandelt werden. Dies hatte nicht nur den Vorteil, daß dem Prediger trotz der scheinbaren Einschränkung eine größere Freiheit bei der Abfassung gegeben wurde - wie er die abzuhandelnden Punkte innerhalb einer ternären Struktur ordnete, blieb seinem Ermessen überlassen -, auch der Hörer wurde so in die Lage versetzt, sowohl Gegenstand als auch Form der Predigt unmittelbarer zu erfassen. Elaborierte Predigten wie die des Roger-Papstes hatten zum Ziel, die Verbindung der drei Divisiones untereinander auch sprachlich kenntlich zu machen. Dieselben sprachlichen Elemente am Anfang jeder der drei abzuhandelnden Punkte sollten nicht nur Einheit in der Vielfalt fördern, sondern ebenso dem Zuhörerohr schmeicheln ${ }^{99}$.

Clemens VI. entschied sich in seinen Konsistorialansprachen für eine divisio intra, eine Untergliederung, die ausschließlich auf den einzelnen Wortbestandteilen des Themas beruhte - Wortbestandteile, die durch waghalsige etymologische Ableitungen oftmals erst bearbeitet werden mußten, um überhaupt predigtkompatibel zu werden ${ }^{100}$. Die Legitimation und Bestätigung der einzelnen Divisonselemente erfolgte mittels Belegstellen aus der Bibel oder durch Anführung anderer auctoritates. Bevorzugt wurde dasjenige Verfahren, das es möglich machte, eine divisio intra durch das Anführen wörtlicher Paral-

99 Vgl. Charland, Artes praedicandi, S.158: „Cette nécessité de trouver, pour l'énoncé de la division, des mots différents de ceux du thème et rimant entre eux, amenait le prédicateur à user d'un vocabulaire assez étrange parfois.«

100 Die Kompliziertheit dieser Vorgehensweise ist für hoch- und spätmittelalterliche Predigtlehren Anlaß, im Falle von an das Volk gerichteten Predigten vehement für eine divisio extra einzutreten. Dieses Gliederungsschema, in dem die einzelnen Divisionspunkte außerhalb des eigentlichen Predigttextes gesucht, in der Folge jedoch mit dem Thema verbunden werden, ist sehr viel besser dazu geeignet, sprachliche und damit auch gedankliche Klarheit bei der Verkündigung zu fördern. 
lelstellen aus der Bibel zu legitimieren. Erst nachdem alle in der Bibel verborgenen Verbindungslinien ausgeschöpft waren, wurden mittels der auctoritates Aussagen (spät-)antiker oder mittelalterlicher Philosophen und Theologen herangezogen.

Für seine Tätigkeit als Prediger griff Clemens VI. mit Vorliebe auf Florilegien und Kompendien zurück, die ihm ein zielgerichtetes Suchen und schnelles Auffinden von Väter- und Klassikerzitaten ermöglichten ${ }^{101}$. Bereits als junger Benediktiner hatte er so in La Chaise-Dieu einen Band mit Auszügen aus und Abschriften von antiken Autoren angefertigt ${ }^{102}$. In seiner Zeit als Erzbischof von Sens kümmerte er sich um die Herausgabe eines Exzerptbandes aus Werken Bernhards von Clairvaux ${ }^{103}$. Als Papst wurden ihm, dem literatissimo sed occupatissimo homini atque ob id talium compendiorum avidissi$m o^{104}$, einige, zum Teil von ihm selbst in Auftrag gegebene Werke dieses Genres gewidmet. Anzuführen sind hier das von Bartolomeo da Urbino verfaßte

$101 \mathrm{Vgl}$. allgemein Jacqueline HAMEssE, Les florilèges philosophiques du XIII ${ }^{\mathrm{e}}$ au XVe siècle, in: Les genres littéraires dans les sources théologiques et philosophiques médiévales. Définition, critique, exploitation. Actes du colloque international de Louvain-la-Neuve (25-27 mai 1981), Louvain-la-Neuve 1982, S.181-191; DIES., Le vocabulaire des florilèges médiévaux, in: Méthodes et instruments du travail intellectuel au Moyen Âge, Turnhout 1990, S. 209-230; DiES., Les florilèges philosophiques, instruments de travail des intellectuels à la fin du Moyen Âge et à la Renaissance, in: Filosofia e Teologia nel Trecento. Studi in ricordo di Eugenio Randi, Louvain-la-Neuve 1994, S. 479-508; Thomas FALMAGNE, Les cisterciens et les nouvelles formes d'organisation des florilèges, in: Archivum Latinitatis Medii Aevi 55 (1997) S. 75-176.

102 Dieser Band ist als Cod. Borgh. 247 in der Biblioteca Vaticana erhalten, vgl. MAIER, Der literarische Nachlaß des Petrus Rogerii 15 (1948) S. 332-356; 16 (1949) S. 72-98, hier S. 94-96. Cod. 247 überliefert als Autographe u.a. ein alphabetisches Sachregister zur Nikomachischen Ethik und ein unvollständiges Inhaltsverzeichnis der Etymologien des Isidor von Sevilla. Die Autorin urteilt: "Der künftige Clemens VI. hat sich also in seinen Studienjahren mit den verschiedensten Wissensgebieten beschäftigt. Neben Theologie und Philosophie haben ihn, genau so wie später im Leben, in starkem Masse die Naturwissenschaften interessiert, [...] er hat sich mit philologisch-humanistischen Studien befasst, und er hat vor allem für die Jurisprudenz eine gewisse Vorliebe gehabt«; vgl. auch Maurice FAuCON, La librairie des papes d'Avignon. Sa formation, sa composition, ses catalogues (1316-1420), 2 Bde., Paris 1887 (Bibliothèque des Écoles françaises d'Athènes et de Rome, 43/50); Marie-Hyacinthe LAURENT, Guillaume des Rosières et la Bibliothèque pontificale à l'époque de Clément VI, in: Mélanges Auguste Pelzer. Études d'histoire littéraire et doctrinale de la scolastique médiévale offertes à Monseigneur Auguste Pelzer, Louvain 1947, S. 579-603; Francesco Migliorino, Un libro di Pierre Roger. Dalla scuola di Bernardo Raimundo alla biblioteca dei papi avignonesi, in: Miscellanea Domenico Maffei dicata, hg.v. Antonio García y Garcia, Peter Weimar, Bd.3, Keip 1995, S. 267-315; Étienne ANHEIM, La bibliothèque personnelle de Pierre Roger/Clément VI, in: La vie culturelle, intellectuelle et scientifique à la cour des papes d'Avignon, hg. v. Jacqueline HAMESSE, Turnhout 2006, S. 1-49.

103 Paris, BnF MS nouvelle acquisition latine 2627, in: BEC 124 (1966) S.153f.: Incipit liber primus exceptionum collectarum de diversis opusculis $b$. Bernardi $[$...] editus ab episcopo Petro Senonensi.

104 Petrarca, Familiares, lib. VIII, ep. 6, hg. v. Vittorio Rossı, Bd. 2, Florenz 1934, S. 173. 
und Augustinus-Zitate alphabetisch auflistende Milleloquium ${ }^{105}$, ein Band mit Exzerpten aus Hieronymus ${ }^{106}$, das alphabetisch geordnete, auch Kommentare umfassende Repertorium der Werke Senecas von Luca Mannelli ${ }^{107}$ oder das Lexikon der Ethik, Ökonomik, Politik und Rhetorik des Aristoteles, verfaßt von Giovanni Bernier de Fayt ${ }^{108}$. Im Widmungsschreiben seiner Tabulatio et Expositio Senecae verwies Mannelli auf die Absicht, dem Papst die possessionem gentilium auctorum fertilem et fecundam zur Verfügung stellen zu wollen, um ihm damit zu ermöglichen, den Verpflichtungen seines Amtes gerecht zu werden, das von ihm nicht nur eine alles überragende Geisteskraft, sondern eine ebenso exzellente Literaturkenntnis und - daran gekoppelt - Redegabe verlange $^{109}$. Ziel des vom Papst in Auftrag gegebenen Repertoriums war das leichte Auffinden und Verwenden von Zitaten Senecas ${ }^{110}$. Die Bildung des Papstes war breitgefächert, seine Kenntnis klassischer Autoren außergewöhnlich. Einer besonderen Wertschätzung konnten sich dabei Augustinus ${ }^{111}$

105 EHrLe, Historia, S. 162. Das vom Papst in Auftrag gegebene Parallelwerk mit Ambrosius-Zitaten blieb unvollendet.

106 Ibid., S. 537f., nn. 1324-1325, wo eine vom Papst in Auftrag gegebene tabula secundum ordinem alphabeti super materiis contentis in omnibus litteris, libris, epistolis, prologis et aliis tractatibus Ieronimi aufgeführt wird.

107 Thomas KAEPPELI, Luca Mannelli e la sua tabulatio et expositio Senecae, in: AFP 18 (1948) S. 237-264.

108 Tabula moralium valde notabilis per alphabetum, edita a magistro Ioanne de Fayt abbate Sancti Bavonis, quam dominus Clemens papa VI fecit scribi, vgl. Bernard HAUREAU, Notice et extraits de quelques manuscrits latins de la Bibliothèque Nationale, Bd.5, Paris 1892, S.78; Martin GrabmanN, Methoden und Hilfsmittel des Aristotelesstudiums im Mittelalter, in: Sitzungsberichte der Bayerischen Akademie der Wissenschaften, philosophisch-historische Abteilung 5 (1939) S. 140; Birger MUNK OLSEN, Les florilèges d'auteurs classiques, in: Les genres littéraires dans les sources théologiques et philosophiques médiévales. Définition, critique, exploitation. Actes du colloque international de Louvain-laNeuve (25-27 mai 1981), Louvain-la-Neuve 1982, S. 151-164.

109 Vgl. KÄPPELI, Mannelli, S.261: Generalis totius ecclesie cathedra et celsitudo tanti status requirit in principe non solum ut ingenio ceteros superet et litterarum peritia singulari subditos antecedat et facundia omnes mortales transcendat quibus est dignitate prestantior.

110 Ibid., S.262: Utilitas huius compilacionis, beatissime papa Clemens, est facilitas inventionis et inventorum eclarationis. Parui ecce voluntati vestre, utinam tam efficaciter quam libenter. Durch die Hinzufügung von Kommentaren und Erläuterungen, die nicht von Seneca stammten, sondern dem gesamten Spektrum der auctores antiqui entnommen wurden, konnte der Papst auf weitere Autoritäten zurückgreifen, ohne dazu ein anderes Kompendium zu verwenden. Die herangezogenen Autoren listet Mannelli auf; ibid., S. 263: utor biblia et beato Augustino, maxime de civitate dei, Ieronimo, maxime in epistolis, Ysidoro ethimologiarum, Fulgentio mitilogiarum, Papia, Ugutione, Prisciano, Aristotile, maxime in ethicis, Tito Livio, Salustio, Paulo Orosio, Iustino, Iulio Celso, Suetonio, Virgilio, Ovidio, Statio, Oratio, Iuvenali, Persio, Apulegio et maxime Valerio, allegando libros unde excipio.

111 Vgl. die Aussage innerhalb der Collatio Nephtalim, in: MS 240, fol. 165va: Modo, reverendi patres et domini, videtur michi, quod eloquia excellentissimi doctoris beati Augustini fuerunt et sunt in veritate firmissima, in sublimitate altissima, in virtuositate efficacissima, in claritate evidentissima, que absque alia prosecutione manifeste apparent sua opera intuenti; 
und Thomas von Aquin ${ }^{112}$ erfreuen. Auf Augustinus gingen letztlich auch die Vorstellungen zurück, die Clemens VI. mit dem Predigtamt verband ${ }^{113}$.

In der wohl Ende der zwanziger Jahre gehaltenen Predigt Benedicam zum Festtag des Heiligen Dominikus listete er die Fehler schlechter Prediger auf ${ }^{114}$. Besonderen Nachdruck legte er dabei auf die in seinen Augen ärgerlichen »Predigtmärlein « - quedam falsa et mirabilia de piscibus, et avibus, et aliis hujusmodi. Gemeint waren damit wohl die sich großer Beliebtheit erfreuenden Exempla, deren illustrative Kraft in den meisten Fällen auf reiner Imagination beruhte 115 . Noch als Papst verzichtete er auf die Verwendung solcher Exempla. Der zweite zentrale Kritikpunkt richtete sich gegen die Neigung vieler Prediger, ihre Aussagen mittels komplizierter Strukturen und elaborierter Rhetorik zu verdunkeln. Diese Kritik beherzigte er selbst als Papst nicht in allen Fällen. Die von ihm in seinen Predigten eingeforderte Wahrheit bzw. Wahrhaftigkeit unterlag gewissen interpretatorischen Beschränkungen. Insbesondere die zur Analyse anstehenden Konsistorialansprachen sind Musterbeispiele für den Umgang mit einer Form von Wahrheit, die sich zumeist als Leerstelle innerhalb des Predigtkontexts manifestiert. Auch dem Verschweigen von Wahrheiten eignet eine Form von Wahrhaftigkeit. Daß an der avignonesischen Kurie jedoch auch andere Predigtstile gepflegt wurden, die sich von dem des Papstes fundamental unterschieden, verdeutlicht die Vita des Petrus Thomas, eines angesehenen Karmeliten, dem es aufgrund der Patronage durch Kardinal Élie Talleyrand de Périgord gelang, zu einem der begehrtesten

vgl. Mollat, Euvre oratoire, n. 26, S. 248. Der alte Katalog verzeichnet allein 87 Bände Augustiniana, die in der Bibliothek zu Avignon aufbewahrt wurden und von der besonderen Stellung dieses Kirchenvaters zeugen, vgl. EHRLE, Historia, S.288-295, nn. 54-140. Weit abgeschlagen landen die übrigen Kirchenväter: Gregor der Große mit 24 Bänden, Hieronymus mit 21 Bänden und Ambrosius mit 13 Bänden, ibid., S. 295-300, nn. 141-198.

112 Vgl. die Bemerkung innerhalb der Collatio Docebat eos, in: MS 240, fol. 399rb: Videtur michi, quod doctrina istius sancti ostenditur vera esse super omnes doctrinas doctorum modernorum; vgl. Mollat, Euvre oratoire, n.9, S.244. Der doctor melifluus war in der päpstlichen Bibliothek mit 86 Handschriften präsent, vgl. EHRLE, Historia, S.303-310, nn. 239-324.

113 Vgl. Balthasar FISCHER, "Nicht wie die Gelehrten reden: eher wie die Ungelehrten «. Eine Mahnung Augustins an den christlichen Prediger, in: Ders., Frömmigkeit der Kirche. Gesammelte Studien zur christlichen Spiritualität, hg.v. Albert GeRHARDS und Andreas HEINZ, Bonn 2000, S. 247-254.

$114 \mathrm{Vgl}$. MS 240, fol. $191 \mathrm{va:}$ Verba veritatis et sobrietatis eloquor contra quosdam qui, quasi Scriptura indigeat mendaciis ad sui confirmationem, inducant in suis predicationibus quedam falsa et mirabilia de piscibus, et avibus, et aliis hujusmodi; contra quosdam etiam, qui magis volunt docere subtilia quam utilia; contra alios etiam, qui prorumpunt in abusum ad opprobia magis et ad convicia quam ad loquendum sobria; [...] contra multos, qui magis predicant subtiliter, clara obscurando, inutiliter curiosa tractando, adulanter placentia loquendo; pauci enim sunt hodie, qui audeant dicere veritatem.

115 Jean-Théobald WELTER, L'Exemplum dans la littérature religieuse et didactique du Moyen Âge, Paris 1927; Claude BrémOND, Jacques Le GoFf, Jean-Claude ScHMITT (Hg.), L'exemplum, Turnhout ${ }^{21996}$ ( Typologie des sources du Moyen Âge occidental, 40). 
Prediger Avignons aufzusteigen, dessen Renommee nicht zuletzt auch darin begründet lag, $\mathrm{da} ß$ er seine Zuhörer zum Lachen brachte ${ }^{116}$.

Die sprachliche Ausgestaltung der divisiones unterlag den Vorgaben der dilatatio. Der Prediger, bemüht, seinen Gedanken vollendete sprachliche Gestalt zu geben, hatte eine Fülle von Hilfsmitteln zur Hand, um einer auch in den Predigtlehren sichtbar werdenden, elementaren Angst entgegenzuwirken: »Having nothing or too little to say seems to have been the primary anxiety of medieval preachers «117. Kaum ein mittelalterlicher Prediger hielt sich an die Auslegung allein der durch das Thema vorgegebenen Elemente. Die Kunst der dilatatio bestand gerade darin, eigenes Gedankengut möglichst geschickt mit den einzelnen Divisionselementen zu verknüpfen. Dabei konnte es sich als nötig erweisen, die einzelnen divisiones nochmals in eine Reihe von subdivisiones, auch distinctiones genannt, zu unterteilen, wobei es zu einem auch bei Clemens VI. spürbaren Ungleichgewicht der einzelnen Elemente zueinander kommen konnte. Das Bemühen um Harmonie im Predigtaufbau stieß hier an seine Grenzen.

Drei Hauptarten der dilatatio lassen sich unterscheiden. Von eminenter Bedeutung waren einmal mehr die auctoritates: biblische Gestalten, Kirchenväter, heidnische und christliche Autoren der Antike. Sie dienten einerseits der gedanklichen Absicherung des Vorgebrachten, traten andererseits aber auch über weite Passagen hinweg an die Stelle des Predigers, der dadurch auf die Entfaltung eigener Gedanken verzichten konnte. In den Konsistorialansprachen Clemens' VI. sind vor allem Gregor der Große mit seiner Regula pastoralis und Bernhard von Clairvaux mit seinem Papstspiegel De consideratione zu nennen. Aus diesen Werken wurde mitunter extensiv zitiert. Einer der Hauptgründe für diese Form der wenn nicht wörtlichen, so doch gedanklichen Übernahme lag in der Tatsache begründet, daß die Vorstellung von der eigenen geistigen Sterilität, das Bewußtsein, neben den Autoritäten nichts Neues mehr sagen zu können, gerade im Spätmittelalter weit verbreitet war ${ }^{118}$. Aber auch der verstärkte Gebrauch von Hilfsmitteln in Form von

$116 \mathrm{Vgl}$. The life of Saint Peter Thomas by Philippe de Mézières, S. 61: In praedicatione sua utique nulli parcebat, nec domino papae, nec cuicumque. In medio vero sermonis communiter homines ridere faciebat; aliqua pulchra moralia narrando, modo flere, modo ridere faciebat, et in fine sermonis sui omnis homo a facie eius aedificatus et consolatus recedebat. Mézières fügt an: Et in tempore suo non erat talis praedicator in ecclesia Dei. Vgl. zur Verwendung von Exempla am Papsthof Blake BEATTIE, The sermon as speculum principis: a curial sermon by Luca Manelli, in: Medieval Sermon Studies 42 (1998) S. 26-51, hier S. 48-50.

117 Marianne G. Briscoe, Artes praedicandi, Turnhout 1992 (Typologie des sources du Moyen Âge occidental, 61), S. 60 .

118 Mittelalterliche Originalität wird dort sichtbar, wo Aussagen unterschiedlicher auctoritates so miteinander verknüpft werden, daß daraus neue Sichtweisen entstehen. Dieses Neue muß inhaltlich jedoch stets auf die durch traditio sanktionierten Meinungen der auctoritates rückführbar sein; vgl. Thomas HAYE, Oratio. Mittelalterliche Redekunst in lateinischer Sprache, Leiden, Boston, Köln 1999 (Mittellateinische Studien und Texte, 27). 
Predigtmanualen und Zitatensammlungen förderte diese Haltung entscheidend. Als weitere Form von dilatatio ist das Verfahren der Argumentation, der kontrastiven Gegenüberstellung einzelner Punkte, zu nennen. Idealiter sollte bei diesem Verfahren jeder vorgebrachte Standpunkt durch die Darlegung des entgegengesetzten Falles bekräftigt werden. Dies schloß auch eine aktive Einbeziehung der Zuhörer über nicht nur rhetorisch gemeinte Fragen mit ein. Auf das dritte, für die mittelalterliche Predigt wohl charakteristischste und von Clemens VI. wenig geschätzte Verfahren wurde bereits verwiesen: die Verwendung von exempla. Auf einen ansonsten von exempla abgedeckten Teilbereich guten Predigens verzichtete der Papst gleichwohl nicht: die Erheiterung seiner Zuhörer ${ }^{119}$. Auch wenn Philibert Schmitz diesem Vorgehen des Papstes mit vernichtender Kritik begegnete ${ }^{120}$, bleibt doch festzuhalten, daß die von ihm erzeugte Heiterkeit weniger die Frucht grobschlächtiger Späße und Vergleiche als vielmehr Ergebnis ironisierender Zuspitzung war ${ }^{121}$.

Der insbesondere den Bibelzitaten inhärente multiple Schriftsinn wurde vom Papst ausgeschöpft. Selten ging er dabei auf den Wortsinn, den sensus litteralis, von ihm als sensus historicus verstanden, ein ${ }^{122}$. Dennoch verzichtete er nicht darauf, seiner Überzeugung Ausdruck zu verleihen, da $\$$ in der Bibel mehrere Litteralsinne miteinander konkurrierten, derselbe Sachverhalt also je nach Zeit und Umständen unterschiedlich interpretiert werden konnte ${ }^{123}$. Häufig bediente er sich der typologischen Form der Interpretation. Darin verwies ein wirklich vorgefallenes historisches Ereignis auf ein ebenfalls wirklich vorgefallenes oder als wirklich vorfallend erwartetes historisches Ereignis ${ }^{124}$. An keiner Stelle schöpfte Clemens VI. die gesamte Bandbreite der vier zur

119 Erheiterung dürfte jedoch niemals wie im Falle des eben erwähnten Petrus Thomasius zu veritablem, mit Lachen verbundenem Amusement geführt haben. Die lauten Töne waren Clemens' Sache nicht: Er bevorzugte das, was heute wohl am ehesten unter dem Begriff Ironie subsumiert wird.

${ }_{120}$ SCHMITZ, Sermons, S. 15: »l'orateur n'avait pas toujours fait preuve d'un goût très fin dans ses calembours, multipliés quelquefois jusqu'à satiété dans un même sermon«.

121 Häufig stützt sich Clemens VI. auf die Etymologie der jeweiligen Kardinalsnamen, um bei seiner Zuhörerschaft ein Schmunzeln hervorzurufen, so beispielsweise in der Collatio Egrediebatur et intrabat, wo Aimeric de Châtelus mit einem Hecht verglichen wird, vgl. Kap. 5.2.2.2.

122 Vgl. Diana WoOD, »...novo sensu sacram adulterare Scripturam«. Clement VI and the political use of the Bible, in: The Bible in the medieval world. Essays in memory of B. Smalley, hg.v. Katherin WaLSH, Diana WOOD, Oxford 1985, S.237-249; vgl. allgemein Pierre SYNAVE, La doctrine de Saint Thomas d'Aquin sur le sens littéral des écritures, in: Revue biblique 35 (1926) S. 40-65. Neben Augustinus war Thomas von Aquin die für den Papst wichtigste Autorität.

$123 \mathrm{Vgl}$. Sicut frigus nivis, MS 240, fol. 250ra-vb; Kap. 5.2.1.2.

$124 \mathrm{Vgl}$. hierzu Erich AuERBACH, Typologische Motive in der mittelalterlichen Literatur, Krefeld 1953, S. 10. 
Verfügung stehenden Schriftsinne aus ${ }^{125}$. Seinen hermeneutischen Bemühungen setzte er des öfteren insofern Grenzen, als er die drei den Wortsinn übersteigenden sensus zu einer einzigen Mischform zusammenfaßte. Anteil am Erfolg einer Predigt hatten die Schmuckformen der Rede, die colores rhetori$c i{ }^{126}$. Ein aus der Antike stammendes Arsenal rhetorischer Stilmittel stand damit auch Clemens VI. zur Verfügung. Der von ihm in seiner Predigttätigkeit verfochtene Nexus zwischen Schönheit und Wahrheit war in nicht unerheblichem Maße Ergebnis des souveränen Umgangs mit einer Vielzahl rhetorischer Mittel. Ein Sermo war in den Augen des Papstes erst dann schön zu nennen, wenn er über die »Wahrheit der Existenz«, die »Erhabenheit der Auszeichnung «, die »Tugend der Wirksamkeit« und die "Klarheit der Einsicht« verfügte ${ }^{127}$. Angesprochen wurde damit das einer Predigt inhärente prodesse et delectare ${ }^{128}$, dem er durch die Verbindung der beiden Elemente Wahrheit und Schönheit zum Durchbruch verhelfen wollte. Falschheit und Niedrigkeit, Eitelkeit und Dunkelheit seien hingegen die Übel, die unbedingt von einer guten Predigt fernzuhalten seien ${ }^{129}$.

Die Predigten Clemens' VI. werden in den Handschriften als sermones und collationes tituliert. Worin der genaue Unterschied zwischen beiden Gruppen besteht, ist dabei nicht immer klar zu erkennen. Grundsätzlich konnte es sich bei einer Collatio um eine Unterweisung handeln, die am späten Nachmittag

$125 \mathrm{Vgl}$. den in seiner Kürze und Dichte noch immer unerreichten Artikel von Friedrich OHLY, Vom geistigen Sinn des Wortes im Mittelalter, in: DERS., Schriften zur mittelalterlichen Bedeutungsforschung, Darmstadt 1977, S. 1-32. Der Memorialvers Littera gesta docet, quid credas allegoria, moralis quid agas, quo tendas anagogia zeigt in seiner Reduktion auf das Wesentliche wohl am besten die unterschiedlichen, der Schrift inhärenten Sinne mit ihrem jeweiligen Bedeutungsspektrum, vgl. hierzu ibid., S. 17; Harry CAPLAN, The four senses of scriptural interpretation and the mediaeval theory of preaching, in: Speculum 4 (1929) S. 282-290; Frank-Rutger HAUSMANN, Französisches Mittelalter, Stuttgart, Weimar 1996, S. 204-213.

126 Vgl. Leonid ARbusow, Colores rhetorici, Berlin 1948. Arbusow bietet eine Auswahl rhetorischer Figuren und Gemeinplätze als Hilfsmittel für akademische Übungen an mittelalterlichen Texten.

127 Vgl. die bisher unedierte Collatio zu Ehren des Heiligen Augustinus Nephtalim cervus emissus, MS 240, fol.162r: Unde videtur michi, quod inter cetera eloquium dicitur habere pulchritudinem ex quattuor, secundum similitudinem pulchritudinis corporalis. Primo quando habet veritatem existentie, secundo quando habet sublimitatem eminentie, tercio quando habet virtuositatem efficacie, quarto quando habet claritatem intelligentie, eloquium enim merito dicitur pulchrum.

${ }^{128}$ Horaz, Ars poetica, V. 333-334: Aut prodesse volunt aut delectare poetae, aut simul et iocunda et idonea dicere vitas.

129 MS 240, fol. 162va-b: Falsitas autem vilitas, vanitas et obscuritas debent esse extranea a sermone. Et ideo quando remota sunt, sermo pulcher est [...]. Et quia hodie prohdolor in multis verbis prelatorum etiam magnorum ista quattuor vel eorum alterum se immiscent, quia frequenter in ore eorum invenitur potius falsitas quam veritas, vilitas quam honestas, vanitas quam utilitas, obscuritas quam claritas, idcirco eorum verba turpitudinem potius quam pulchritudinem habent. 
oder Abend stattfand und oftmals den zweiten Teil einer am Vormittag begonnenen Predigt darstellte ${ }^{130}$. Des weiteren konnte der Collatio ein familiärer, ja freundschaftlicher Umgangston eignen ${ }^{131}$. Oft wurde unter dem Schlagwort »Collationes« auch eine Predigtreihe über ein- und dasselbe Thema verstanden ${ }^{132}$.

Im Falle Clemens' VI. ist der bereits 1928 von Guillaume Mollat vorgebrachten Deutung der Vorzug zu geben. Er sah in den Collationes Prunkreden, die der Akzentuierung besonderer politischer oder religiöser Ereignisse dienen sollten, worunter insbesondere die anläßlich von Kardinalskreationen und der Rückkehr von Kardinallegaten an die Kurie gehaltenen Ansprachen zu fassen seien ${ }^{133}$. Allerdings ginge man fehl in der Annahme, die Handschriften überlieferten Predigten, deren Ausarbeitung und sprachliche Gestalt vollkommen sei. Selbst die der Memoria Clemens' VI. in sermonibus gewidmete Handschrift MS 240, die als codex unicus die anläßlich von Kardinalskreationen verfaßten Collationes enthält, bietet nur in den allerseltensten Fällen einen Predigttext, dessen Ausarbeitung als abgeschlossen gelten könnte. In den meisten Fällen erweist sich ein Urteil darüber, ob das, was dem Leser vor Augen steht, eher elaborierte Schemata als endgültig ausformulierte Ansprachen sind, als ausgesprochen heikel ${ }^{134}$. Als aussichtslos darf gar das Bemühen

130 Über den in Avignon geschätzten Prediger Pierre Thomas wird berichtet, er habe mehrmals am Tag - collationibus cardinalium post prandium exceptis - gepredigt, vgl. The life of Saint Peter Thomas, S. 60. Die Einführung dieser Predigtform wird dem zweiten Ordensgeneral der Dominikaner, Jordan von Sachsen, zugeschrieben, der über die Untätigkeit der Novizen an den Nachmittagen der Sonn- und Festtage derart erzürnt gewesen sein soll, daß er zwecks Unterdrückung des verderblichen Müßiggangs eine theologische Unterweisung nach der Mittagsmahlzeit, der klösterlichen collatio, zwingend vorschrieb, vgl. Albert LeCOY DE LA MARCHE, La chaire française au Moyen Âge, Paris 21886, S. 225; vgl. KIENZLE, Sermon, S. 369.

131 In diesem Sinne interpretiert Isidor von Sevilla den Begriff, vgl. Isidor von Sevilla, De ecclesiasticis officiis, II, 16, 14, in: PL 83, Sp. 800.

132 Vgl. Louis-Jacques BATAILlON, De la lectio à la praedicatio. Commentaires bibliques et sermons au XIII ${ }^{e}$ siècle, in: Revue des sciences philosophiques et théologiques 70 (1986) S. 559-575, hier S. 562f.

133 Vgl. Mollat, CEuvre oratoire, S. 242: »le mot collationes s'applique par extension à des allocutions d'apparât faites à propos d'événements politiques ou religieux, à l'occasion de promotions cardinalices ou du retour de légats à la cour pontificale«; vgl. in diesem Sinne auch Pierre JugIE, Un discours inédit du cardinal Gui de Boulogne, légat en Espagne, prononcé devant le roi d'Aragon (24 janvier 1359), in: Les prélats, l'Église et la société. Hommage à Bernard Guillemain, Bordeaux 1994, S. 219-227, hier S.219: un discours, très proche dans la forme du sermon, prononcé généralement à l'occasion de grand événements politiques ou diplomatiques par une haute autorité ecclésiastique. Dans les textes contemporains, le terme désigne, le plus souvent, un discours fait par le pape en consistoire public, lors du retour à la Curie d'un cardinal légat ou de la réception de souverains ou d'ambassadeurs d'un certain rang «. Fournier rückt Collationes inhaltlich in die Nähe von Vorträgen, vgl. Fournier, Pierre Roger, S. 226.

134 Nur wenige Beispiele sind erhalten, bei denen sowohl die ursprüngliche reportatio als auch ihre Ausarbeitung vorliegen, vgl. dazu Nicole BÉRIOU, La reportation des sermons 
gelten, auf die Frage antworten zu wollen, ob in den vorliegenden Ansprachen eventuell vom Autor selbst stammende Notizen aufgegangen sind oder es sich bei ihnen eher um verschriftlichte Resümees, reportationes, handelt, die von einem Kleriker aus der Zuhörerschaft stammen ${ }^{135}$. Die Existenz solcher reportatores an der Kurie ist belegt. Ein Angehöriger des Augustinereremitenordens konnte sich so beispielsweise am Ende der 1343 gehaltenen Ansprache Desidero vos videre als Reportator verewigen ${ }^{136}$.

Die Art der Redaktion läßt sich für die zur Untersuchung anstehenden sermones also nicht sicher bestimmen. Was jedoch keinerlei Zweifel unterliegt, ist die Sprache, in der Clemens VI. seine Konsistorialansprachen hielt. Der Maxime lingua romana coram clericis saporem suavitatis non habet folgend ${ }^{137}$, wählte er die einzige seiner illustren Zuhörerschar angemessene Sprache, das Lateinische. Daß sich der Papst in seiner Zeit als Kardinal auch des Französischen zu Predigtzwecken bediente, bezeugen mit Accingimini und Quia dominus zwei Ansprachen, die sich nicht ausschließlich an Kleriker

parisiens à la fin du XIII ${ }^{e}$ siècle, in: Medioevo e Rinascimento 3 (1989) S.87-125; DIES., Latin and the vernacular. Some remarks about sermons delivered on Good Friday during the Thirteenth Century, in: Die deutsche Predigt im Mittelalter. Internationales Symposium am Fachbereich Germanistik der FU Berlin (3.-6. Oktober 1989), hg. v. Volker MERTENS, Hans-Jochen SCHIEWER, Tübingen 1992, S. 268-284.

135 Das in den Collationes häufig vorkommende non prosequor, evtl. noch ergänzt durch ein causa brevitatis kann wohl am ehesten mit der konkreten Predigtsituation in Verbindung gebracht werden, während ein im Text aufscheinendes Expone (vgl. MS 240, fol. 422rb) wohl eher als Gedächtnisstütze aufzufassen ist, die dem Papst eventuell in Form einer kleinen Notiz vorlag.

136 Vgl. Heinrich Schmidinger, Die Antwort Clemens' VI. an die Gesandtschaft der Stadt Rom vom Jahre 1343, in: Miscellanea in onore di Monsignor Martino Giusti, prefetto dell'Archivio segreto vaticano, Bd. 2, Città del Vaticano 1978, S. 323-365 (neu abgedruckt in: Patriarch im Abendland. Beiträge zur Geschichte des Papsttums, Roms und Aquileias im Mittelalter. Ausgewählte Aufsätze von Heinrich Schmidinger. Festgabe zu seinem 70. Geburtstag, Salzburg 1986, S. 125-169), hier S. 167: quam responsionem ego frater Bernardinus de Urbeveteri, fratrum heremitarum O.S.A., solum audiendo in publico consistorio supradictum summum patrem et dominum nostrum nichil pro tunc scribendo collegi et fideliter reportavi. Bernardinus ist auch als Reportator einer Predigt von Kardinal Bertrand du Pouget belegt. Der Sermo findet sich in einer im Pembrok College zu Cambridge aufbewahrten Hanschrift, vgl. JAMES, A descriptive catalogue, n. 98 , fol. $94 \mathrm{v}-98 \mathrm{v}$ : Reportatio fratris Berardini de urbe veteri fratris heremitarum sancti Augustini ordinis de sermone facto in capella papae per reverendum in Christo patrem et dominum dominum Bertrandum episcopum Hostiensem et Vellatrencensem cardinalem in tercia dominica XL in civitate Avinionensi anno domini MCCCXLIIII tempore sanctissimi in Christo et domini Clementis divina providencia papae VI sui pontificatus anno tercio etc., vgl. hierzu auch Jacqueline HAMESSE, Collatio et reportatio: deux vocables specifiques de la vie intellectuelle au Moyen Âge, in: Actes du Colloque Terminologie de la vie intellectuelle au Moyen Âge, hg. v. Olga WeIJERs, Turnhout 1988, S. 78-87; DIEs., La méthode de travail des reportateurs, in: Medioevo e Rinascimento 3 (1989) S.51-67; Kap. 5.1.10.

137 Zit. in LeCoy DE LA MARChe, Chaire, S. 249; vgl. auch Longère, Prédication, S. 164; KIENZLE, Sermon, S. 971. 
richteten ${ }^{138}$. In der konkreten Predigtsituation wählte Clemens VI. wohl einen Mittelweg zwischen der freien Rede und dem Ablesen eines vorbereiteten Textes ${ }^{139}$. Eindrücklich wird einem dies in der Collatio Obsecro vos, die in mancher Beziehung eine Sonderstellung einnimmt, vor Augen geführt ${ }^{140}$. Die Ansprache anläßlich der Kreation von Kardinal Guillaume de la Jugée beginnt mit einer Skizzierung des in der Folge nur bedingt beachteten Predigtaufbaus und umfaßt Schlüsselbegriffe, die nachfolgend weiter ausgeführt werden. Clemens VI. nutzte den Predigtakt, um seine umfassende Kenntnis der Heiligen Schrift unter Beweis zu stellen. Daß dieser Kenntnis durch Verwendung von Bibelkonkordanzen nachgeholfen wurde, wird spätestens dann ersichtlich, wenn der Papst für einen innerhalb der jeweiligen Predigt zentralen Begriff einen Großteil der Bibelstellen zitiert, in denen eben dieser Begriff auftaucht ${ }^{141}$. Die dominierende Position des Alten Testaments wird dabei deutlich. Allein neun der zwölf in dieser Arbeit detalliert behandelten Collationes weisen ein dem Alten Testament entnommenes Thema auf ${ }^{142}$. Eine Bezugnahme auf immerhin zwei anläßlich von Kardinalskreationen gehaltene Ansprachen erfolgt in den Vitae paparum Avionensium ${ }^{143}$. Dort wird zusätzlich hervorgehoben, daß dem Papst auch an der korrekten formalen Ausübung seines Amtes gelegen gewesen sei, habe er doch Konsistorien und Gottesdienste zu den geforderten Zeiten abgehalten und dabei oft ausgezeichnete

138 Vgl. Mollat, Euvre oratoire, nn. 49, 73. In der Collatio Accingimini et estote filii potentes (MS 240, fol. 308vb-314rb) machte sich der Papst vor dem Hintergrund der zwischen England und Frankreich schwelenden Auseinandersetzungen Gedanken über Krieg und Frieden und kam dabei zu folgendem Ergebnis: Videtur michi, quod quilibet debeat se parare ad istam pugnam tripliciter: Primo en faysent a Dieu de ses mesfaiz satisfaction, secundo en ayent souvent bon amis et consultation, tercio en faysent de ce qui est besong bonne provision (fol. $313 \mathrm{vb}$ ).

139 Vgl. zur Frage Mündlichkeit versus Schriftlichkeit KIENZLE, Sermon, S. 423-430.

140 Vgl. Kap. 4.2 .

141 Der Papst wollte und sollte seine Zuhörerschaft durch Bibel- und Autoritätenkenntnis beeindrucken. Insbesondere im Falle der mitunter gebündelt angeführten Bibelstellen wird jedoch schnell deutlich, daß die Vorgehensweise zumeist dem Bemühen entsprang, Dilatationselemente entsprechend zu unterfüttern. Insofern ist der wenig schmeichelhaften Bemerkung Mollats zuzustimmen, daß »les livres saints n'ont sans doute d'attrait pour lui que parce que ce sont de riches mines de textes servant à justifier ses artifices oratoires «, in: MoLLAT, Euvre oratoire, S.267. Für die Zeitgenossen waren Redegabe und phänomenales Gedächtnis des Papstes untrennbar miteinander verbunden. Letzteres soll Frucht einer in Jugendjahren davongetragenen Verletzung gewesen sein, vgl. Petrarca, Rerum memorandarum liber 1; Sexta Vita, in: Baluze/Mollat, Vitae I, S. 262 .

142 Assumpsi michi duas virgas: Zach 11,7; Loquere tu et audiemus: Ex 20,19; Fecit in domo: II Chr 3,10; Super montem excelsum: Jes 40,9; Ibant et revertebantur: Ez 1,14; Hii sunt viri: Esdra 2,1; Sicut frigus nivis: Prov 25,13; Egrediebatur et intrabat: I Reg 18,13; Legatus fidelis sanitas: Prov 13,17. Dem NT wird das Thema in folgenden Fällen entnommen: Obsecro vos: Eph 4,1; Videntibus illis: Act 1,9; Homo quidam nobilis: Lc 19,12.

143 Vgl. BaluZe/Mollat, Vitae I, S. 269 (Videntibus illis), S.280/281 (Assumpsi michi duas virgas). 
sermones und collationes gehalten ${ }^{144}$. Integraler Bestandteil des päpstlichen Amtes war also eine regelmäßige Predigttätigkeit, die - excellentissime ausgeführt - über den engen Bereich der Kurie ausstrahlte. Der von Clemens VI. gepflegte Redestil, dessen typische Elemente wie die überbordende Verwendung von Assonanzen nebst Atomisierung der scholastisch geprägten divisio in Einzelsätze und Einzelworte das Verständnis des Gesamtzusammenhangs oftmals erschwert, schwang sich weit über die Vorgaben eines sermo humilis auf und konnte so zumindest für den Bereich der feierlichen und offiziellen Predigt beispielhaft wirken.

144 BaluZE/Mollat, Vitae I, S.259f.: In hiis enim multum solempniter se habuit, utpote consistoria et consilia debitis temporibus indefectibiliter tenendo, divina officia celebrando, sermones et collationes excellentissime etiam sepe faciendo; in quibus etsi retroactis temporibus forte quandoque habuerit sibi pares excedentes tamen raro, prout talium tenor adhuc penes plures permanens indicat manifeste. 
